\title{
A Multidimensional Investigation of Sexuality in Older Adults Within a Successful Aging Model
}

\author{
Allyson S. Graf \\ West Virginia University
}

Follow this and additional works at: https://researchrepository.wvu.edu/etd

\section{Recommended Citation}

Graf, Allyson S., "A Multidimensional Investigation of Sexuality in Older Adults Within a Successful Aging Model" (2013). Graduate Theses, Dissertations, and Problem Reports. 535.

https://researchrepository.wvu.edu/etd/535

This Thesis is protected by copyright and/or related rights. It has been brought to you by the The Research Repository @ WVU with permission from the rights-holder(s). You are free to use this Thesis in any way that is permitted by the copyright and related rights legislation that applies to your use. For other uses you must obtain permission from the rights-holder(s) directly, unless additional rights are indicated by a Creative Commons license in the record and/ or on the work itself. This Thesis has been accepted for inclusion in WVU Graduate Theses, Dissertations, and Problem Reports collection by an authorized administrator of The Research Repository @ WVU. For more information, please contact researchrepository@mail.wvu.edu. 
A Multidimensional Investigation of Sexuality in Older Adults Within a Successful Aging Model

\author{
Allyson S. Graf, M.A. \\ Thesis submitted to the \\ Eberly College of Arts and Sciences \\ at West Virginia University \\ in partial fulfillment of the requirements \\ for the degree of
}
Master of Science
in
Psychology

Julie Hicks Patrick, Ph.D., Chair

Amy Gentzler, Ph.D.

Natalie Shook, Ph.D.

Department of Psychology

Morgantown, West Virginia

2013

Keywords: Sexuality; Sexual Well-Being; Successful Aging; Middle Aged; Older Adults 


\title{
ABSTRACT \\ A Multidimensional Investigation of Sexuality in Older Adults Within a Successful Aging Model
}

\begin{abstract}
Allyson S. Graf, M.A.
Sexual well-being in later life has traditionally been evaluated in relation to age-related physical limitations and sexual dysfunction. This study developed a multidimensional model of sexual well-being by investigating sexual interest, sexual attitudes (general and age-specific), and agespecific sexual knowledge in relation to more commonly-used indicators of sexual well-being (e.g., frequency and sexual satisfaction). Using a racially-diverse, U.S. sample of adults $(N=$ $\left.367, M_{\text {age }}=54.40\right)$, structural equation modeling was used to test these associations (AGFI = .967 ; TLI $=.994 ;$ and RMSEA $=.031)$. Sexual interest $(\beta=.53)$, attitudes $(\beta=-.11$ and .17$)$, and knowledge $(\beta=.09)$ accounted for $33.1 \%$ of the variance in a latent construct of sexual wellbeing. Multi-group comparisons revealed a different pattern of associations by gender with the model accounting for more variance in women's sexual well-being than men's $(40.1 \%$ vs. $25.9 \%)$. Sexual interest contributed significantly to both men's $(\beta=.46)$ and women's sexual well-being $(\beta=.60)$. Men's sexual well-being was also influenced by their general sexual attitudes $(\beta=.19)$, but not by either age-specific measure. Sexual attitudes did not contribute to women's sexual well-being, but age-specific sexual knowledge contributed significantly $(\beta=$ .13). These findings demonstrate the importance of considering more than physical capability when studying sexuality beyond the childbearing years. Further, beyond sexual interest, men and women appear to differ slightly in what impacts sexual well-being. Because these particular constructs are subjective and social in nature, it may reflect differences in sexual socialization.
\end{abstract}




\section{Table of Contents}

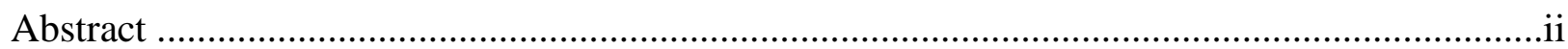

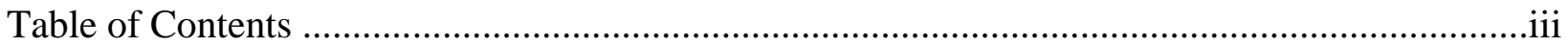

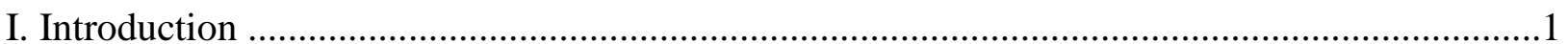

A. Developmental Paradigms for Studying Sexuality \& Aging .......................................

B. Conceptual Models Relating the Importance of Sexuality in Mid- and Late Life ..........3

C. Aging \& Sexuality: What is Known ………………...............................................

D. Methodological Weaknesses in the Extant Literature ................................................11

II. Specific Aims and Research Hypotheses ………….........................................................14

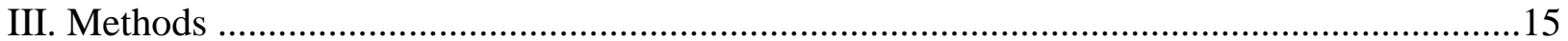

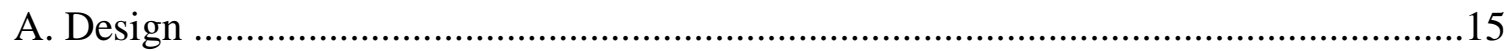

B. Sampling \& Participant Selection ........................................................................16

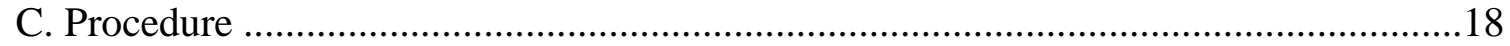

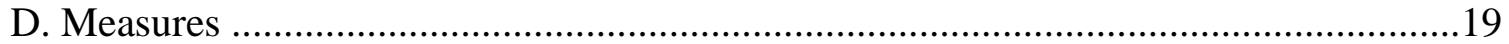

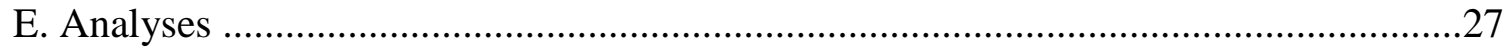

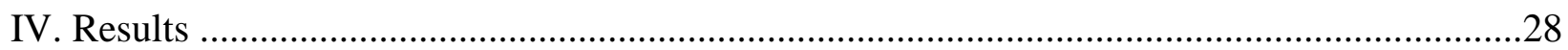

A. Preliminary Analyses: Bivariate Relationships …………………………………......28

B. Univariate Assessment of Group Differences \& Similarities.........................................31

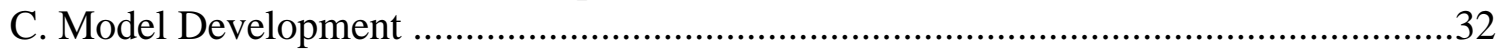

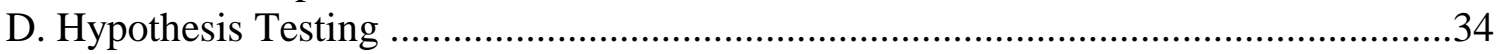

E. Redefining Successful Aging: Where Does Sexual Well-being Fit? ...........................36

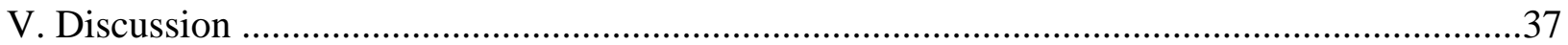

A. A More Comprehensive Model of Sexual Well-Being ..................................................37

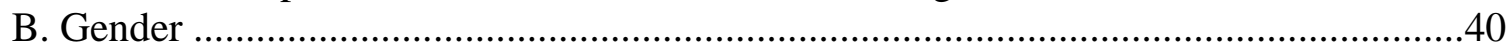

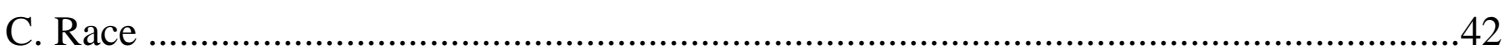

D. Sexual Well-Being as a Distinct Pillar of Successful Aging ………………………...43

E. Limitations \& Progress ..........................................................................................44

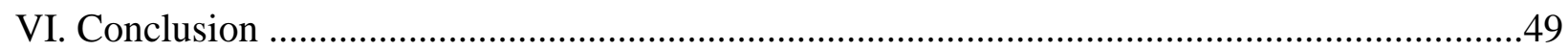

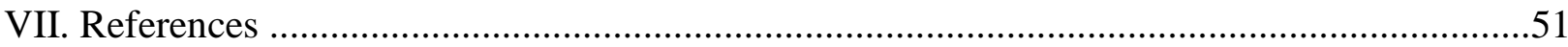

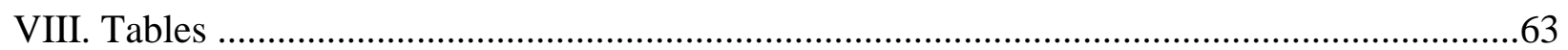

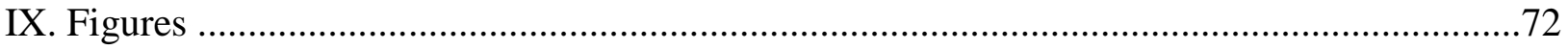

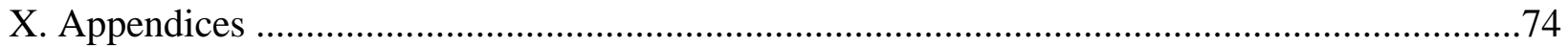




\section{Introduction}

Sexuality is a multidimensional construct which includes identity, interest/desire, opportunity, physiological functioning, attitudes and values, expression, and satisfaction (DeLamater \& Friedrich, 2002; Dennerstein, Hayes, Sand, \& Lehert, 2009; Kinsey, Pomeroy, \& Martin, 1948; Parker, 2009; Waite, Laumann, Das, \& Schumm, 2009). Sexual activity, while driven by biological impetus, also occurs within social, cultural, psychological and historic contexts (DeLamater \& Karraker, 2009; Guan, 2004; Zeiss \& Kasl-Godley, 2001). Although adolescence is commonly recognized as an important developmental period related to sexuality (DeLamater \& Friedrich; Mosher \& Danoff-Burg, 2005), sexuality remains an important aspect of the human experience across the lifespan (AARP, 1999; Hillman, 2011; Lindau \& Gavrilova, 2010). Until recently, however, the intersection of sexuality and aging has rarely been examined empirically.

When sexuality and aging have been examined empirically, researchers have frequently focused on physiological dysfunction (Parker, 2009). This medical model has dominated the aging and sexuality literature. A high proportion of this work focuses solely on reduced sexual functioning as a symptom of aging. With the advent of prescription drugs capable of remedying erectile dysfunction, such as Viagra and Cialis, researchers anticipated vast differences in reported sexual activity in aging adults. This singular focus on biological capacity disregards important psychological (desire and identity) and social (attitudes and values) elements of sexuality (Schiavi, 2010; Steinke, 1994). Several developmental models are available which might provide a better framework for understanding sexuality and aging.

\section{Developmental Paradigms for Studying Sexuality and Aging}

DeLamater \& Karraker (2009) discuss the sexual life cycle as non-linear. While sexual activity and desire may remain relatively high and level off following the childbearing years, 
there may be resurgence in mid-life as children leave home and couples reconnect intimately. Women experience menopause, and thus, are no longer at risk of becoming pregnant. As couples near old age, however, a decline may again occur as roles change. Unemployment and financial instability are common, and partners begin to confront illness and mortality. While some of these changes can be described as normative age-graded events, non-normative life events such as partnership transitions (early widowhood, divorce, new relationship formation) or unexpectedly becoming a caregiver for a partner may also create change in an individual's sexual development (DeLamater \& Friedrich, 2002). The current older generations have also experienced historygraded life events related to sexuality, including the sexual revolution, increased access to birth control and abortion, and the AIDS epidemic. These events brought to light different aspects of sexuality and challenged traditional conceptions. Acknowledging normative age-graded, historygraded, and non-normative life events is a dynamic of the life-span development theory that is useful in explaining individual differences in a developmental trajectory (Baltes, 1987).

Development is best understood from a multidisciplinary approach (Baltes, 1987). Tolman and McClleland (2010) differentiated sexual development, the physical and biological aspects, from sexuality development - a multidimensional construct accounting for not only physical, but social, emotional and cognitive aspects as well. Patterns of gains, losses, and adaptations are extremely relevant when considering sexuality and aging. As older adults age, there are normative declines in sexual function; however, those who desire to remain sexually active and express interest will often find alternative means to remain active. This compensation is often best conceived in the context of a mutually loving and respectful relationship (Weeks, 2002). Those without a partner may alter their outlook on the importance of sex to quality of life, but agree that if a partner were present, sex may become important again (Skultety, 2007). The 
way in which an older adult navigates the gains and losses associated with sexuality across fluctuating contexts illustrates the plasticity of sexuality.

\section{Conceptual Models Relating the Importance of Sexuality in Mid- and Late Life}

Global models of well being historically center on subjective appraisals of life satisfaction and the prevalence of positive and negative affect in one's life (Diener, 1984). More recently, domain-specific satisfaction is also considered (Diener, Suh, Lucas, \& Smith, 1999). Several influences have been considered in evaluating well being including health, cognitive abilities, and demographic variables including age, marital status, and education. Demographics have been found to account for minimal variability in subjective well-being (Diener). Theoretical models incorporating personality dimensions, life goals, culture, and coping mechanisms (intrinsic factors) have been useful in explaining differences in navigating particular life circumstances (extrinsic factors) and protecting one's sense of well being (Diener et al.; Matsumoto et al., 1999).

Well being was originally believed to be a product of the youthful and healthy (Diener, 1984). In contrast, successful aging paradigms state that well being can be maintained across the lifespan. In shifting focus away from the restrictions seemingly imposed by aging, researchers sought to define models of successful aging. Common themes include: good physical and mental health, protective activities, functional status, and social support (Blazer, 2006; Lang, Rohr, \& Williger, 2011; Rowe \& Kahn, 1997). Blazer illustrates that many of these models focus on objective measures while successful aging is generally more subjective and relative to what individuals deem important in life. Components such as good health are often not rated as highly important to older adults when asked to appraise their level of successful aging. 
Subjective well-being and the criteria for successful aging are ultimately based on attitudes. Attitudes as a construct are multi-faceted with definitions that include affect, interest, knowledge, experience, and behavioral tendencies (Olson \& Zanna, 1993). Several theories support attitudes as antecedents of behavior (theory of reasoned action, MODE model, theory of planned behavior), but others acknowledge the bidirectional nature in how behavior impacts attitude, such as Bem's self-perception theory and the theory of cognitive dissonance (see Olson \& Zanna for a complete review). This bidirectional relationship may be useful in understanding the interplay of sexual attitudes and sexual expression in middle-aged and older adults.

\section{Aging \& Sexuality: What Is Known}

Gender differences. Much of the knowledge concerning sexuality in mid- to late adulthood concerns gender differences; though, like most reported gender differences, effect sizes are often small and not as meaningful as assumed (Hyde, 2005). Beyond middle age, men and women have been shown to differ in sexual functioning (DeLamater \& Friedrich, 2002; DeLamater \& Karraker, 2009; Rheaume \& Mitty, 2008), sexual motivations (including interest) (Bancroft, 2007; Dennerstein et al., 2009; Fugere, Escoto, Cousins, Riggs, \& Haerich, 2008), perceived barriers to sexual activity (Beckman, Waern, Gustafson, \& Skoog, 2008; Lindau et al., 2007), sexual satisfaction (Laumann et al., 2006), and sexual attitudes and values (Bonds-Raacke \& Raacke, 2011; Mosher \& Danoff-Burg, 2005). Biological (i.e., hormonal differences and longevity) and social (i.e., gender roles and stereotypes) influences may account for gender differences in sexuality in late life.

Physical function \& health. Considerable biological change begins in mid-life for both men and women that would suggest at least some decrease in sexual functioning. Without hormone replacement therapy, both estrogen and testosterone levels for most women drop below 
the necessary levels for responsive sexual reaction, affecting desire and bodily preparedness (DeLamater \& Friedrich, 2002). A similar hormonal decline in men (andropause) results in limited sexual function. Existing research suggests steady biological declines in sexual functioning, resulting in less frequent and less physically satisfying sexual encounters into the later years. This decline can be explained not only by reduction of relevant sex hormones, but also by higher incidences of chronic illness (AARP, 1999; Araujo, Mohr, \& McKinlay, 2004; Bancroft, 2007). Psychological conditions, such as depression, as well the medications prescribed for its treatment may also limit sexual activity (DeLamater \& Karraker, 2009). The National Institute of Mental Health (2010) suggests that the risk for developing depression increases with age, with one to five percent of community-dwelling senior citizens and more than $50 \%$ of those in residential care facilities meeting diagnostic criteria.

While physical health and chronic illness relate to sexual activity across the lifespan, it is often cited as the main cause for sexual inactivity in adulthood, especially in men over the age of 55 (Lindau et al., 2007; Matthias, Lubben, Atchison, \& Schweitzer, 1997). This is not to say that health is an insignificant issue for women; Matthias and colleagues demonstrated the complex interplay of gender, health, and sexual activity in a sample of very old adults (ages ranged from 70-94). Self-reported health was predictive of sexual activity in men, but in women it was the functional aspects of health (as captured by instrumental activities of daily living and number of days reported where one wanted to remain in bed) that were predictive of sexual activity. Taking data from two, nationally-representative data sets (MIDUS, including adults spanning 25-74 years, and NSHAP, spanning 57-85 years), Lindau and Gavrilova (2010) showed that both men and women who reported very good to excellent health were more likely to be sexually active and reported doing so more frequently. Some studies, however, do not support 
the link between self-reported health and sexual activity (Eisenberg, Shindel, Smith, Breyer, \& Lipshultz, 2010), and others minimize the impact of biological factors in light of sociocultural influences (Guan, 2004).

With age, both men and women report more episodes of troublesome sexual dysfunction (DeLamater \& Karraker, 2009). Erectile dysfunction has been linked to medical conditions, such as hypertension, diabetes, high cholesterol, and smoking. Similarly, both prescription and overthe-counter medications can increase the likelihood of sexual dysfunction. Given the occurrence of sexual dysfunction, Lindau and colleagues (2007) reported that almost half of both men and women ages 57 to 85 reported a bothersome sexual problem, including lack of interest and difficulty becoming aroused in women and erectile dysfunction in men. Individuals wishing to remain sexually active may call on their sexual knowledge and values to find ways to remain sexually expressive despite these limitations (Lindau \& Gavrilova, 2010).

DeLamater \& Karraker (2009) indicated that those with sexual dysfunction come to a crossroads of whether to discontinue all sexual acts or become more creative with their sexual expression. By inquiring about activities beyond intercourse, more can be learned about alternative forms of sexual behavior. The Modern Maturity Sexuality Study conducted by AARP (1999) conceptualized sexual activity to include both intercourse as well as non-intercourse expression, such as kissing, sexual touching, oral sex and self-stimulation. Results indicated more frequent reports of these non-intercourse activities.

Sexual interest/desire. One of the most consistent gender differences in sexuality pertains to sexual interest with men reporting more interest across the lifespan (Baldwin \& Baldwin, 1997). Reports from middle-aged and older women indicate that interest corresponds with having a partner (Beckman et al., 2008; DeLamater \& Karraker, 2009; Dennerstein et al., 
2009). Women, on average, live longer than men. In the Modern Maturity Sexuality study (AARP, 1999), women 75 and older were significantly less likely to have a sexual partner than men of the same age (58\% versus $21 \%$ ). Women in late life, therefore, may adapt by reducing the value placed on sex and substitute other activities in place of sexual activity (AARP, 1999). Female widows are also less likely to engage in post-marital relationships especially later in life (DeLamater \& Friedrich, 2002).

Sexual attitudes, values, and identity. Culture and historical time period influence perceptions of sexuality (Fugere et al., 2008). Relying on theories of stereotype accuracy and "the kernel of truth" hypothesis presented by Lee, Jussim, and McCauley (1995), there may be aspects of stereotypic beliefs that are true, but gross overestimation of the prevalence, frequency, or extent make certain assertions inappropriate. Weeks (2002) has demonstrated a pattern of overestimation resulting from ageist beliefs regarding the prevalence of sexual dysfunction in the elderly. Steinke (1994) furthers this argument, suggesting that limited knowledge of what actually happens physically and functionally with increased age may contribute to faulty attitudes or beliefs concerning sexuality in later life.

A correlation between sexual knowledge and attitudes has been demonstrated, indicating that more knowledge about sexuality relates to more permissive attitudes (White, 1982). This relationship, however, is moderated by other influences such as education, race, closeness of elderly relationships, and religion (Allen, Petro, \& Phillips, 2009; Hillman \& Stricker, 1994). Without adequate knowledge then, people are more likely to rely on hearsay and public opinion in evaluating sexuality (DeLamater \& Karraker, 2009). This is detrimental to middle-aged and older adults because the societal perspective in most cultures treats sexuality in the aged as unnecessary and inappropriate. If this message is perpetuated by caregivers, medical 
professionals, and family, it could result in diminished desire to foster sexual relationships (Rheaume \& Mitty, 2008). Greater sexual knowledge and more permissive attitudes have been shown to predict engagement in sexual activity in participants over the age of 60 (Steinke, 1994; Wang, Lu, Chen \& Yu, 2008).

Few studies have compared differences in attitudes of middle-aged and older adults across gender or culture. Mosher and Danoff-Burg (2005) demonstrate how understanding the gender-specific development of agentic versus communal personality traits through socialization may help explain why men are more willing to engage in non-committal sexual relationships and why women value marriage. Depending on the values placed on marriage within a given culture, this may also result in differences in perceived barriers to sexuality beyond mid-life.

A literature review completed by Fugere and colleagues (2008) summarized research on gender and ethnic differences in sexual attitudes. All of the studies reviewed were based on adolescent and young adult samples. Consistently, men reported more permissive sexual attitudes than women. However, there is evidence to suggest that sexual attitudes between the sexes have converged on some dimensions, such as premarital sex. Collectively, Asian Americans were found to have the most conservative sexual attitudes, which were paralleled with reports of less sexual activity. African Americans showed the most permissive attitudes and endorsed earlier and riskier sexual behaviors.

Ahrold and Meston (2010) surveyed over 1,500 undergraduates from European, Asian, and Hispanic backgrounds about their sexual attitudes. Though effect sizes were small, cultural differences did exist on some sexual attitudes. There was evidence that acculturation and religiosity moderated these differences. While these differences in sexuality have been 
documented in younger populations, relatively little is known about these differences in middleaged and older populations.

While personal attitudes are one of the best predictors of behavior, social norms play an equal if not greater part in sexual behavior. This may be of particular importance for women who may be more sensitive to others due to communal personality characteristics. For instance, Rheaume and Mitty (2008) suggest that attitudes of nursing home staff and adult children may have the biggest impact on sexual inactivity in older adults. Matthias and colleagues (1997) documented the impact of social networks as a predictor of sexual activity in old-old adults (older than 70 years); surprisingly, social networks were predictive only for men. Adults (between the ages of 56 and 75 years) tend to perceive their spouses and doctors as the most supportive in discussions of sexual health (as cited in Bonds-Raacke \& Raacke, 2011). Yet, few report consulting with their doctors about sexual issues (Emmers-Sommer et al., 2009). Further, some doctors report unease with approaching older adult patients about sexual health concerns, especially if patient-providers are of the opposite gender.

Access to knowledge. Adults may have limited access to adequate sources of sexual knowledge. For many older adults, the knowledge they have surrounding sexual expression and practices is very limited as their opportunity for exploration was prior to the sexual revolution when sex was still intrinsically tied to reproduction. While individual differences may exist in terms of knowledge and experience, several older adults admit wanting more information pertaining to sexual expression, sexual dysfunction, and sexual risks. Gott (2001) investigated the occurrence of sexually risky behaviors in a sample of adults (ages 50-90 years) in the United Kingdom. Most reported receiving very limited information about STI and HIV prevention, but 
$25 \%$ wanted to learn more. Men reported being twice as likely as women to seek out information concerning sexual dysfunction (AARP, 1999).

As middle-aged and older adults become increasingly comfortable with technology, the Internet may also be a resource for obtaining sexual knowledge. A study completed on 6,279 young-old adults (63-66 years) found that one-third had used the Internet to search for healthcare information (Flynn, Smith, \& Freese, 2006). The best predictors of whether older adults were likely to use the Internet in this capacity were education and openness-to-experience. A recent ethnographic study completed by Harrod (2011) suggested that elements of one's identity (age and health status) may influence the type of information sought online as well as how that information is used.

Sexual satisfaction. Sexual satisfaction is a complex variable that is best addressed via a multidimensional approach. Bancroft (2007) suggested this complexity when he noted gender differences not only in satisfaction, but also in goals or motivations. The Modern Maturity Sexuality Study conducted by AARP in 1999 revealed a consistent pattern in gendered satisfaction among 1,384 adults aged 45 and older. Females' sexual satisfaction was explained by their sexual attitudes, attributes of their sexual partners, and self-concept. Males, contrary to stereotype, reported that romance and a partner who was sensitive to their needs increased sexual satisfaction. Araujo and colleagues (2004) suggested that satisfaction may be a construct that is highly susceptible to cohort effects.

In an investigation of sexual attitudes and behaviors spanning 29 countries, satisfaction was conceptualized into 4 components of sexual well-being: emotional satisfaction, physical satisfaction, satisfaction with personal sexual health and function, and the importance of sex in life (Laumann et al., 2006). Emotional and physical satisfaction were highly correlated and 
combined into "relational satisfaction." Across all nations, men were generally more satisfied than women (which is a common finding across the literature-AARP, 1999; Araujo et al., 2004), but interestingly, a cluster analysis revealed three distinct patterns of sexual satisfaction demonstrating a cultural influence. In comparing two of these clusters, countries with more gender-equal attitudes (Western Europe, North America, Australia) indicated the highest levels of satisfaction; countries with more male-centric attitudes (Mediterranean and Asian cultures) had lower levels of sexual well-being yet some reported that sex was more important to life than those with more gender-equal beliefs. This suggests that sexual attitudes encapsulated in a culture come to bear on personal sexual satisfaction.

\section{Methodological Weaknesses in the Extant Literature}

While a recent increase in research has begun to refute the stereotype that sexuality beyond the childbearing years is atypical, much of this research has been descriptive in nature, limited in generalizability, lacking in adequate measures applicable to older adults and limited in scope. The primary focus has been on sexual dysfunction.

Non-theoretical foundations. Sexuality has been acknowledged as a multidimensional phenomenon, presenting not only as behaviors or activity, but also in terms of desire, values, attitudes, knowledge, and satisfaction. But sexuality is often not studied in this way. Few studies attempt to incorporate theory, instead opting to describe some facet of sexuality in a chosen population. For example, ecological system theory could be useful in illustrating the influence of broader developmental contexts as they come to bear on an individual's sexuality. Past applications, however, have been limited, including differences between heterosexual and lesbian women in sexual satisfaction (Henderson, Lehavot, \& Simoni, 2009), sexual therapy and 
intervention programs (Jones, da Silva, \& Soloski, 2011; Kirana et al., 2009), and risky sexual behaviors in adolescents (Bersamin, Todd, \& Remer, 2011; Tolman, Striepe, \& Harmon, 2003). Theoretical foundations have been used sparingly in the aging and sexuality literature as well. Guan's (2004) use of Bronfenbrenner's classic model in explaining sexual activity and attitudes in an elderly Chinese population looked to account for cultural and societal implications while also considering historical and chronological events in one's lifetime. This application has also been documented more recently in Shea's (2011) field research of practices and attitudes in elderly Chinese women. Beyond these applications, however, theories of sexuality as a multidimensional construct in the aging literature are virtually non-existent because the purpose has been to identify whether sexual behavior is still occurring into old age and comparing trends in frequency, expression, and satisfaction to those of middle-aged and younger adults.

More recently, sexual health and well-being are beginning to be considered in relation to other health and well-being outcomes. According to Schiavi (2010), modern conceptions of sexuality fit within a successful aging framework, which accounts for the multiple ways to achieve success or well being despite common age-related changes. Initial work in this area has found support for integrating the study of sexuality in mid- to late life with successful aging components, including health, cognitive abilities, and subjective measures of quality of life (Thompson, Charo, Vahia, Depp, Allison, \& Jeste, 2011; Woloski-Wruble, Oliel, Leefsma, \& Hochner-Celnikier, 2010). These studies, however, have been relatively rudimentary in their analytical approaches and interestingly, limited to female samples.

Sampling. With the exception of the National Social Life Health and Aging Project (NSHAP — a longitudinal investigation of understanding health, intimacy, and social networks) that purposefully oversampled on key demographics of interest, many studies are limited in 
generalizability by their sample demographics. Despite the growing ethnic diversity of the United States (one in three citizens self-identify as ethnic minorities) and the global trend of an aging population, much of the research focuses narrowly on White and Western European standards (Hillman 2011). Because perceptions of old age generally differ across race (Lichtenstein, 2006) and ethnic differences have been documented concerning sexual attitudes in younger age groups (Fugere et al., 2008), it is plausible that ethnicity/race will also affect sexuality in old age.

A recent study conducted by Huang and colleagues (2009) on 1,977 women aged 45-80 years found racial differences on several sexuality measures. African American women reported significantly higher levels of sexual desire than White women, but also significantly less sexual activity. Latinas reported being more sexually satisfied than White women. These findings suggest that the sexual lives of middle-aged and older adults may potentially differ as a function of one's racial/ethnic background, but more work is necessary.

Other sampling biases found in the extant literature include: limitations on homosexual responding (if sampled, typically excluded from analysis), exclusion criteria including certain forms of health and/or mental complications, and selection bias (those participating versus those not participating may be doing so because of the study content). Once samples are collected, important individual differences are often diluted through statistical control rather than being investigated as potential influences on sexuality.

Constructs. As discussed previously, sexuality is most often represented by only one or two measures. Frequency and satisfaction are the most often reported measures of sexuality, but even in this most simplified form, comparison of results found in the literature are muddied by inconsistent definitions of what constitutes sexual expression and satisfaction. To understand 
sexuality (as with most complex constructs) it must be examined in a multivariate manner, accounting for biological, interpersonal, and ecological influences (DeLamater \& Karraker, 2009). With few exceptions, this multivariate approach to sexuality is absent in the literature. Reflecting societal perspectives, the commonly employed medical model represents a biased perspective of sexuality in aging, focusing primarily on the associated medical problems and often not acknowledging influences beyond basic capacity.

Measurement instruments. Measures and scales used to quantify sexual knowledge, attitudes, and behaviors are primarily derived from the adolescent and young adult literature. Without proper validation of these instruments in middle-aged and older populations there are increased chances of either missing important variations across adulthood or claiming relationships between variables that are not entirely true. New measures or adaptations of existing measures are necessary to prevent these threats to construct validity. Validation with aging and diverse populations may be increasingly necessary as cohorts with potentially different perspectives (especially in terms of sexuality) reach old age.

\section{Specific Aims and Research Hypotheses}

Guided by a successful aging framework in which well being is a multiply determined, multidimensional construct (Lang et al., 2011), data from a large, multi-racial sample of middleaged and older adults was used to test the following hypotheses.

\section{Specific Aim 1: Approach sexuality as a multidimensional construct and determine} whether gender differences continue to exist in relation to the individual components.

H1: Sexual expression (in terms of frequency and satisfaction) will be associated with an individual's sexual attitudes, interest, and knowledge (DeLamater \& Friedrich, 2002; Dennerstein et al., 2009; Kinsey et al., 1948; Parker, 2009; Waite et al., 2009). 
H2: Gender will influence mean levels of sexual attitudes, interest, knowledge, frequency and satisfaction with men reporting greater interest and more permissive sexual attitudes (AARP, 1999; Fugere et al., 2008; Laumann et al., 2006; Schiavi, 2010). The same pattern of association between sexual attitudes, interest, and knowledge and sexual well-being is expected for each gender.

\section{Specific Aim 2: Expand the knowledge of sexuality and aging with a multi-racial sample} large enough to compare between group differences with multivariate analysis.

RQ: What impact will race have on the associations among sexual attitudes, interest and knowledge with sexual frequency and satisfaction?

Specific Aim 3: Integrate sexuality as an additional pillar of the successful aging model, aligning its importance in late life alongside physical and psychological well-being.

H3: Sexual well-being (defined in relation to frequency and satisfaction) will positively relate to multiple domains of healthy aging, including self-reported health, self-reported mental health, and affective well-being (see Figure 1). This finding will be consistent with previous research of the relationship between measures of sexuality and physical as well as psychological well-being (AARP, 1999; Rheaume \& Mitty, 2008; Weeks, 2002), but incorporate a more complete model of sexuality in mid- to late life.

\section{Methods}

\section{Design}

Analyses were performed on data collected for the Health Behaviors and Knowledge Survey (HBKS) conducted at West Virginia University. The online study investigated health literacy and health behaviors in a sample of middle-aged and older adults, stratified by 
race/ethnicity. Sexual behaviors, attitudes, and knowledge were reported as domain-specific aspects of health behavior.

\section{Sampling and Participant Selection}

The HBKS targeted 600 adults ages $45+$ years, stratified equally by race/ethnicity (White, African American, and Hispanic American). These three racial/ethnic groups were the focus of the current investigation because there are well-documented sexuality differences within younger populations between these groups (i.e., Fugere et al., 2008). Furthermore, because the research question posed was exploratory in nature, the selection of racial/ethnic groups was kept consistent with recent research (Huang et al., 2009) looking at these differences in middle-aged and older adult populations. Few studies to date have looked at middle-aged and older adult, Asian American participants, though more have been conducted within Asian countries (i.e., Ford \& Chamratrithirong, 2012; Moore, 2010; Shea, 2011). Therefore, for the sake of complexity, the sample was limited to only three racial/ethnic groups.

Participants were recruited for the online-only study through Amazon's Mechanical Turk. Mechanical Turk is an "online labor market" wherein individuals can post or locate human intelligence tasks (HITs) to be completed for a pre-specified amount of Amazon credit (Mason \& Suri, 2012). Anyone can register as a worker and payment is often contingent on completing the task according to requester specifications. Mechanical Turk is becoming increasingly used as a recruitment venue for online research studies. While the average age of a Mechanical Turk worker is approximately 32 years, Mason and Suri found the distribution to approximate other online participant pools.

A pilot sample $(N=69)$ was collected using a procedure identical to the live study to insure the sample demographics desired could be obtained using Mechanical Turk. Preliminary 
inspection of these data indicated Mechanical Turk would be an appropriate venue for recruitment. The live study HIT was posted for seven days. When this timeframe closed, 572 surveys had been returned. Individuals who completed the pilot study did not differ significantly on demographic characteristics from this larger sample so the data were combined to yield 641 completed surveys. Of these, 128 were excluded due to incomplete data (less than $50 \%$ of the survey completed or no demographic information), 75 were below the targeted age range, 12 identified as other races/ethnicities, and 23 failed validation checks.

This left 403 participants who met age (45+) and race/ethnicity (White, African American, and Hispanic American) sampling requirements. From this pool of participants, the sample was trimmed due to low response rates in certain demographic categories (detailed below). Three cases were removed because of incomplete data on key measures, even following mean imputation. One case was excluded due to a suspicious pattern of response across all measures.

Two cases were excluded based on a decision to cap the age range at 75 , the common distinction between young-old and old-old (Neugarten, 1974). Participants were also asked to indicate their sexual orientation using a modified version (5 point scale instead of 7) of the Kinsey Sexual Orientation scale (Kinsey et al., 1948). Almost all participants identified as heterosexual (92.8\%). Eleven individuals identified as bisexual and 18 identified as homosexual. Given the low response rate and potential differences in sexuality other than orientation (i.e. Cohler \& Galatzer-Levy, 2000), these 29 individuals were removed from analyses.

The final sample included 367 participants with a mean age of 54.40 years $(S D=7.95)$. The sample was near evenly split on gender (50.1\% male). In terms of ethnic/racial breakdown, 52.6\% were White, $27.5 \%$ were African American, and 19.9\% were Hispanic American. Thus, 
although not equally sized, the cells were sufficiently large to provide adequate power to detect mean differences as indicated by a post hoc power analysis in $\mathrm{G}^{*}$ Power (Faul, Erdfelder, Lang, $\&$ Buchner, 2007). A sample of $n=73$ per group had adequate power ( $>.80)$ to detect mediumsized $\left(f^{2}=.15 ; p<.05\right)$, mean-difference effects.

Most participants were married or cohabitating (64.9\%). The remaining portion of the sample was divorced (14.4\%), single (12.3\%), or widowed (8.4\%). Marital status did not significantly differ by gender or race, but did significantly differ by age group $\left(\chi^{2}(3, N=367)=\right.$ $37.84, p<.001$ ). Middle-aged adults (under the age of $60 ; n=241$ ) accounted for $70.2 \%$ of the married or cohabitating individuals in the sample, $16.1 \%$ of the widowed individuals, and $66 \%$ of the divorcees.

Just under $80 \%(n=283)$ of the entire sample had at least some post-secondary education with 48.6\% having earned a Bachelor's degree or higher. Once again, educational attainment did not differ by gender or race, but did significantly differ by age group $\left(\chi^{2}(5, N=358)=18.29, p\right.$ $=.003)$. Middle-aged adults were more likely to engage in post-secondary education at all levels than older adults, accounting for $68.8 \%$ of individuals reporting some college, but no degree, $88.9 \%$ of individuals with an Associate's degree, $60.9 \%$ of those with a Bachelor's degree, and $67.8 \%$ of those with post-baccalaureate degree.

\section{Procedure}

Participants responded to a posted HIT on Mechanical Turk's Worker HITs tab. The survey was accessed by visiting a secure web address hosted by Survey Monkey. After reading a brief cover letter detailing the study and its purposes, respondents consented to participation by clicking a radial dial and continuing into the survey. A number of assessments ascertaining 
current preventative health behaviors and health literacy were completed. All survey questions are included in Appendix A.

A participant had the option upon completion to click on a hyperlink allowing them to sign up for future research conducted by the investigators; this hyperlink existed as a completely separate survey and could not be linked back to the completed survey. Fifty-five participants chose to complete the additional information. Once finished, they returned to the Mechanical Turk website and entered a code that included their birth year for validation purposes. Honorarium was awarded as a \$5.00 Amazon.com credit (as an agreement with Mechanical Turk indicates).

\section{Measures}

Measures relevant to the current investigation are detailed below. Functional and emotional well-being measures were of particular importance to the original focus of the HBKS. The sexuality questions were included to represent a specific domain of health behaviors and knowledge in addition to the more general health assessments used. Araujo and colleagues (2004) elaborated that gathering sexual behavior data may benefit from this methodological format wherein the main purpose of the investigation is not the sexual components, thus those who did not participate did not necessarily do so because of the sexual component.

Means and standard deviations for all relevant variables are indexed in Table 1. Unless otherwise reported, variables and scales were normally distributed. Missingness was low (> 2\%), and based on inspection of patterns of missing data within and between cases, can be considered ignorable (Howell, 2009). Scale scores with missing data were imputed using individual means on completed items. 
Physical well-being. Often considered to be the "gold standard" of subjective quality of life, the Short Form Health Survey (SF-12) has been implemented internationally and demonstrates adequate validity across racial, ethnic, and international samples (Jenkinson, Chandola, Coulter, \& Bruster, 2001). The four subscales of the Physical Component Summary (PCS) of the SF-12 (Ware, Kosinski, \& Keller, 1996) were used to index physical well-being. These included Physical Functioning, Role-Physical, Bodily Pain, and General Health. For each of the subscales, raw scores were converted to scale scores by summing scale items together, subtracting the number of items from that total, dividing by the item response range and multiplying by 100. Higher scores indicate better health.

The Physical Functioning Subscale combines two items $(\alpha=.71)$ concerning limitations to particular actions, such as climbing stairs. The sample mean was $75.21(S D=28.38)$, indicating minimal limitations to physical functioning in the current sample. The Role-Physical Subscale focuses on physical health as an impediment to certain activities or roles. The reliability for the Role-Physical Subscale was .77 with a mean of $63.42(S D=43.36)$. General Health and Bodily Pain are each measured by a single-item. The general health of the sample was consistent with prior study norms $(M=60.16, S D=24.51$; see Anderson, Mühlbacher, Nübling, Schupp, \& Wagner, 2007 for norms). The sample reported minimal interference caused by bodily pain, $M=$ 76.63, $S D=24.25$.

Psychological well-being. Psychological well-being was indexed by multiple measures. Each is detailed below.

PGC Positive and Negative Affect Scale. The Philadelphia Geriatric Center (PGC) Positive and Negative Affect Scale (Lawton, Kleban, Dean, Rajagopal, \& Parmelee, 1992) asks participants to rate the frequency (Never, Rarely, Sometimes, Frequently, Very Frequently) of 
experiencing each of five positive affective states and five negative affective states in the past week. Each scale ranges from 5 to 25. For Positive Affect (PA), the sample mean was 17.65 (item $M=3.53, S D=3.37$ ) with lower occurrences of Negative Affect (NA; $M=12.72$, item $M$ $=2.54, S D=4.02$ ).

The scales have been shown to be internally consistent $(\alpha=$.77) (Patrick, Cottrell, $\&$ Barnes, 2001) and respective scales correlate highly with measures of depression, mood states, and affect balance (Lawton et al.). In this sample, reliabilities on each of the subscales were adequate $(\alpha=.80$ for PA, $\alpha=.86$ for NA).

Global happiness. A single item, "I believe my life to be..." was used to indicate subjective happiness. Respondents used a 7-point scale, ranging from extremely happy to extremely unhappy. This variable had a mean of $5.06(S D=1.27)$ and was negatively skewed. The skew is common of this form of assessment of well being and is often included as only one indicator among many of well being (Galinha \& Pais-Ribeiro, 2009). Thus, no transformation was performed.

Mental Component Summary of the SF-12. The Mental Component Summary (MCS) of the SF-12 was also used. Four subscales comprise the MCS, including Vitality, Social Functioning, Role-Emotional, and Mental Health (Ware et al., 1996). Vitality and Social Functioning are single, Likert-scale items. With respect to vitality (referenced in the item as energy), the sample had a mean of $55.59(S D=23.59)$. Physical and mental health did not greatly hinder participant social activities $(M=74.39, S D=24.23)$.

The Role-Emotional Subscale is similar to the Role-Physical Subscale, but instead of limitations caused by physical health, mental health disturbances are substituted. Emotional health $(M=72.73, S D=39.51, \alpha=.72$.$) appears to have less of an effect on accomplishments$ 
and limitations in kinds of work than physical health $(t(362)=4.49 . p<.001)$. The Mental Health Subscale asks about frequency of two states: depression and peace. The current sample had a mean of $65.59(S D=20.83)$. The reliability was .70 . All reliability coefficients fall within the range (.63-.91) provided across all subscales by Ware and colleagues (1996) during validation.

Sexual components-Sexual experience. In the HBKS, participants were asked three items pertaining to experience. The first was an open-ended self-portrayal in response to the statement, "Using single words or short phrases, describe your sexual history." The second experience question concerned the recency of particular sexually-related events in an adults' life. The majority of the sexually-related events were adapted from Tobin's (2011) Sexual Attitudes and Experiences Scale (SAES), a recently developed scale of sexual attitudes and experiences validated with an undergraduate population. Given the increasing rates of STIs and HIV diagnoses in older adults (Gott, 2001), four additional experience items were added to assess history of risky sexual behaviors. The final question related to experience was Kinsey’s Heterosexual-Homosexual Rating Scale as a measure of self-identified sexual orientation (Kinsey et al., 1948). While these three measures were included, the sexual orientation scale was the only one used in this project (as described above).

Sexual interest and activity. Sexual activity in previous research has not been consistently defined. The current study used the definition that is established in the current and ongoing research from NSHAP. Sexual activity was defined as, "any mutually voluntary activity with another person that involves sexual contact, whether or not intercourse or orgasm occurs" (Lindau et al., 2007, p. 763). Participants were given this definition and told to use this criterion for questions that referenced sexual activity. 
Participants rated their current interest in sex from absent to degrees of weak or strong appeal (Dennerstein et al., 2009). On a 6-point scale, the mean of the self-reported interest item was $3.82(S D=1.22)$. This question was asked before participants were asked to report involvement in self-stimulation or partnered sexual activity in the past year.

The percentage of participants reporting sexual activity with a partner in the past year (72.0\%) was consistent with previous studies (DeLamater \& Karraker, 2009; Dennerstein et al., 2009) with demographic characteristics similar to the present study (i.e., the majority were middle-aged, $65.7 \%$, and married, $64.9 \%$ ). Those who reported being sexually active were more likely to be married/cohabitating or single $\left(\chi^{2}(3, \mathrm{~N}=367)=68.14, p<.001\right)$ and middle-aged $\left(\chi^{2}(3, N=367)=12.16, p<.001\right)$. An affirmative answer to partnered sexual activity led to follow up questions in regards to duration of their current relationship (DeLamater and Karraker, 2009) and frequency of sexual activity with a partner (Daily, Weekly, Monthly, Quarterly, Twice a Year). With the original scaling, the distribution of the frequency item was bimodal and interpretation difficult because of unequal units ( 2 times, 4 times, 12 times, etc.). To ease interpretation and smooth the distribution, response categories were collapsed into never (28.3\% reporting), occasionally (25.9\%), and frequently (45.8\%). While not all participants were engaged in some form of sexual activity, only $3 \%$ reported no sexual interest when asked directly.

Sexual satisfaction. Those who reported partnered sexual activity in the past year $(n=$ 263) also reported on overall satisfaction as well as three components of sexual satisfaction: physical, emotional, and frequency. In one of the few studies available on sexuality, aging, and cross-cultural differences, Laumann and colleagues (2006) assessed sexual well-being through four separate measures, including physical and emotional satisfaction. They discovered that often 
these last measures correlate highly $(\alpha=.80)$ and can be combined into one factor of relational satisfaction. The same method was applied with frequency satisfaction and was then compared to the overall satisfaction measure as a way of determining whether these aspects of satisfaction account for overall satisfaction.

The mean of global sexual satisfaction was $3.40(S D=1.08)$, indicating average ratings of good. Participants were able to indicate their reasons for dissatisfaction. The most commonlyreported reasons included: partner's lack of interest (36.6\%), personal lack of interest (30.4\%), and personal, non-sexual health problems (17\%). The satisfaction component measures were another way to indicate where dissatisfaction may arise. Satisfaction was generally moderate on all the subcomponents. On a 5-point scale, the mean level of physical satisfaction was $3.52(S D=$ $.99)$, emotional satisfaction was $3.68(S D=1.06)$, and satisfaction with frequency was $3.13(S D$ $=1.05)$.

NSHAP interest and mores. The NSHAP Sexual Interest Scale (Waite et al., 2009) was created by combining responses on the importance of sex to life and the frequency at which one thinks about sex. The mean was $6.03(S D=1.96)$, on a 10-point scale. Previous research using this scale has shown alphas of .76. The scale reliability in the current sample was .67 , which is not uncommon for 2-item scales (Schmidt, Le, \& Ilies, 2003).

Sexual attitudes, beliefs and values were evaluated using two separate measures. The NSHAP Sexual Mores scale is a 5-item measure of general sexual attitudes (Waite et al., 2009) with higher scores indicating more conservative views. Items address attitudes on extramarital sex (see Appendix A); other questions looked at a participants' level of agreement with several statements in regards to casual sex (sex without love), conflicting beliefs (intersection of religion with sexual behaviors), satisfaction (satisfaction is key in a relationship), and continuation of 
sexual activity into later life. The sample mean was $14.43(S D=3.47)$, indicating more traditional sexual values within the sample. Reliability was consistent with previous reports $(\alpha=$ $.76)$.

ASKAS-Attitude Subscale. The Aging Sexuality Knowledge and Attitude Scales (ASKAS) were designed to address sexual attitudes and knowledge specific to older adults. It was originally designed and validated for use with older adults as part of a NIMH-sponsored investigation (White, 1982), but has since been applied and deemed valid with other populations, such as college students, nursing home staff, and adult children of older adults with reliability coefficients greater than 0.85 in most populations (Allen et al., 2009; Bonds-Raacke \& Raacke, 2011; Hillman \& Stricker, 1994). Reliability in the current sample was comparable $(\alpha=.91)$. The use of the ASKAS in addition to the more general sexual attitude items of the NSHAP questions was necessary to address whether attitudes pertaining to older adults represents a specific domain of sexual attitudes separate from general beliefs held about sexuality.

The 26-attitudinal items address commonly held beliefs concerning declining interest in older adults and the appropriateness of sexual contact, especially in the context of institutionalized living conditions (nursing homes, assisted living facilities, etc.); these are rated on a 7-point Likert scale corresponding to agreement or disagreement with the statements. Scores reflect a continuum of sexual attitudes from conservative to permissive. The distribution of scores $(M=74.17, S D=21.89)$ was equivalent to those found by White $(1982)$ for those who had some relation to aged people, but were not older adults themselves.

ASKAS-Knowledge Subscale. The remaining 35 knowledge items of the ASKAS are answered in True-False responding, with a third option "don't know" to discourage random guessing. The knowledge items cover topics ranging from declining interest, declining sexual 
function, sexual risks to health and well being, and other common misconceptions that are factually-based as opposed to socially-defined. The ASKAS has been used previously to indicate the impact of educational intervention on knowledge and attitudes about older adults and sexuality (i.e., Steinke, 1994).

Typically, the knowledge subscale is scored such that lower scores indicate greater knowledge (see White, 1982); however, scoring was modified in the current study to ease interpretation. Scale scores ranged from 0-70 with higher scores indicating more knowledge. The sample mean was $43.96(S D=14.85)$. The reliability was .92 , consistent with other samples. Inspection of the skewness coefficients indicated a violation of normality $(-.85, S E=.13)$ in the form of a negatively skewed distribution. Given that many of the statistics being utilized are robust to departures from normality (Howell, 2009), the variable was not transformed.

STI knowledge. Previous studies have acknowledged that older adults admit limited knowledge about sexual risks (Rheaume \& Mitty, 2008; Gott, 2001). Few studies have investigated this knowledge in an older population and thus, few measures were available that had been demonstrated valid with older populations. The measure used in the HBKS was from a five-year investigation of adolescent sexuality-related knowledge from the Finnish KISS survey. Two true or false questions assessed knowledge of contraceptive purpose ("Contraceptive pills protect against STIs" and "Condoms are the only contraceptive protecting against STIs"). Additionally, respondents were asked to list as many contraceptive methods as they could and to list as many STIs as they could; naming three or more for each was considered "good knowledge” (Part, Rahu, Rahu, \& Karro, 2008). The only adaptation made was in the instructions given to respondents. It was believed that older adults may not be familiar with the terminology sexually transmitted infections so they were instructed, "The following questions 
concern your knowledge of sexually transmitted diseases (STDs) also referred to as sexually transmitted illnesses (STIs) or venereal diseases.”

The most commonly listed STIs were HIV (72\%), gonorrhea (68.5\%), and herpes $(57.7 \%)$. The most commonly reported contraceptive methods were male condoms $(92.6 \%)$ followed by birth control pills ( $86.9 \%)$. Using the scoring method suggested by Part and colleagues (2008), a maximum score of 8 could be earned. The distribution for this knowledge measure was also negatively skewed $(M=6.48, S D=1.80$, skew $=-1.38, S E=.13)$. Once again, this scale was not transformed for the reasoning indicated earlier.

Demographics. Demographic data relevant to the current investigation included age, sex, race/ethnicity, marital status, and education. Age, sex, marital status, and race were of primary concern; these specific demographics are represented prominently in the literature as sources of difference in reported sexual activity, satisfaction, and attitudes.

\section{Analyses}

The data were cleaned and evaluated against the statistical assumptions for the proposed statistical analyses. Independent sample t-tests and ANOVAs were used to investigate mean differences between genders and racial/ethnic groups prior to moving on to multivariate modeling.

Hypothesis 1, which sought to measure sexual well-being through assessment of sexual frequency and sexual satisfaction and demonstrate differences as a function of attitudes, interest, and knowledge (as presented in Figure 1) was assessed with structural equation modeling, using AMOS. AMOS estimates path models through variance-covariance matrices and reads a path diagram as input (Arbuckle, 1995). This also allowed for examination of Hypothesis 2 pertaining 
to the influence of gender on the mean levels of the multiple constructs; beta weights from the resulting model were examined and critical ratio differences were assessed for significance.

Hypothesis 3 was examined with an exploratory factor analysis in order to examine the linear functions of the sexual well-being measures and the physical and psychological well-being measures. Resulting factors were rotated through the direct oblim procedure, which allows for some degree of intercorrelation between the factors, and corrected with Kaiser normalization, retaining factors with eigenvalues greater than 1.0.

\section{Results}

\section{Preliminary Analyses: Bivariate Relationships}

Table 2 displays the correlations among the key demographic variables and all relevant measures. Consistent with previous findings, age was negatively related with reports of partnered sexual activity $\left(r_{p b}=-.25\right)$ and frequency $\left(r_{b}=-.29\right)$. A negative association was found between age and sexual interest $(r=-.23)$.

Participant gender was coded with men as "1" and women as "2." For race, those who identified as White were "1,” African American were "2," and Hispanic American were "3." Participant gender was associated with interest $\left(r_{p b}=-.27\right.$ and -.29 , depending on the interest measure), and general sexual attitudes $\left(r_{p b}=.26\right)$. An additional finding between gender and sexual risk knowledge also emerged $\left(r_{p b}=.22\right)$; race was also weakly related to sexual risk knowledge $\left(r_{p b}=-.16\right)$. Attitudes pertaining to older adult sexuality were also associated with race $\left(r_{p b}=.20\right)$.

The sexual satisfaction measures did correspond strongly to one another. The relationship between physical and emotional satisfaction $(r=.67)$ indicated that these measures could be combined as Laumann and colleagues (2006) did to obtain a measure of relational satisfaction. 
Satisfaction with frequency of sexual activity also correlated strongly with these two items, which led to combining the three items into a single scale $(\alpha=.96)$. This scale was then compared with the single item on global sexual satisfaction and a high correlation was indicated $(r=.93)$. While global sexual satisfaction related adequately with interest $(r=.32)$ and frequency of sexual activity $(r=.45)$, it did not relate to knowledge or attitudes.

Similar to the high level of correspondence between satisfaction measures, the single item on sexual desire and the NSHAP sexual interest scale were highly correlated $(r=.68)$. Adding the direct question of sexual desire to the NSHAP items improved the scale reliability ( $\alpha$ $=.79$ ). Sexual interest generally related as anticipated with behavioral items ( $r$ s from .29 to .46) as shown in Table 2. Sexual interest was not related to sexual knowledge, but did correspond moderately with sexual attitudes (both general and age-specific, $r$ ranging from -.22 to -.31) such that those with greater interest were also less conservative. Frequency of sexual activity in the past year was most strongly related to sexual satisfaction $\left(r_{b}=.45\right)$ and interest $\left(r_{b}=.51\right)$. Greater frequency of sexual activity in the past year did relate to less conservative age-specific attitudes $\left(r_{b}=-.22\right)$

In the current sample, the relationship between the ASKAS subscales was modest $(r=-$ .24). Interestingly, risk knowledge corresponded more strongly with age-specific attitudes $(r=-$ .41). There was a weak relationship between the two knowledge measures, indicating minimal overlap. Greater correspondence was found between the two attitude measures $(r=.28)$, such that harboring permissive or conservative sexual values translates from the general to the more specific.

Few of the well-being variables were related to age, gender, or race. For age, this is inconsistent with previous work in which age often negatively relates to physical health and 
positively relates to psychological well-being (Carstensen, Pasupathi, Mayr, \& Nesselroade, 2000; Karlamangla, Tinetti, Guralnik, Studenskil, Wetle, \& Reuben, 2007). Gender was not related to any of the well-being measures. Finally, research on health disparities often indicates widening gaps with age between Whites and minority groups with respect to self-reports of physical health. This relationship was not found in the present study.

The physical and psychological well-being measures were shown to relate appropriately. Components of physical health, including overall general health, physical functioning, role physical, and bodily pain related strongly and positively with one another $(r=.42$ to .60$)$. The subscales of the MCS (Role-Emotional, Vitality, Social Functioning, and Mental Health) were more modestly related, but in the appropriate direction $(r=.31$ to .56$)$. The correlation coefficients for the additional psychological well-being measures (PGC Affect subscales and Global Happiness item) were all relatively strong except for Social Functioning ( $r$ less than .27 for both PGC Positive Affect and Global Happiness).

In evaluating the bivariate relationships among sexuality and well-being measures, clear patterns of association emerged. There were very few instances in which sexual attitudes or knowledge (global or age-specific) related to health. Sexual activity frequency was related most strongly with subjective happiness $(r=.30)$ with most other psychological well-being coefficients significant, but smaller ( $r$ s ranging from .12 to .23 as shown in Table 2 ). Sexual frequency activity also correlated modestly with the four indicators of physical well-being $(r=$ .14-.28). While causality or even directionality cannot be implied, these findings are consistent with reports that those in better health (mentally and physically) may often stay sexually active.

Overall sexual satisfaction correlated highly with ratings of happiness $(r=.42)$, and moderately with Vitality $(r=.35)$ and Positive Affect $(r=.25)$. The only physical element that 
correlated significantly with sexual satisfaction was General Health $(r=.20)$. This pattern was consistent even among different satisfaction elements. Self-reported interest was also related to both mental and physical health elements $(r=.23-.27)$.

\section{Univariate Assessment of Group Differences \& Similarities}

Gender. Preliminary tests were conducted to investigate mean differences on the demographic variables of interest: gender and race. An independent samples $t$-test was utilized to determine gender differences for knowledge, attitudes, sexual interest, overall satisfaction, and frequency. A Bonferroni-correction was made to the alpha levels to accommodate the multiple tests (Howell, 2009). A significant Levene's test for risk knowledge was anticipated given the skew of this variable; thus, more cautious approaches were utilized for interpreting these results.

Significant differences were found between men and women on risk knowledge, $t$ (329.96) $=-4.21, p<.001$, Cohen's $d=.45$. Cohen's $d$ was calculated using an online calculator (www.uccs.edu/ lbecker/). Common distinctions for effect sizes suggested by Cohen (1992) include small (.20-.49), medium (.50-.79), and large (.80 and greater). Significant effects of gender were also found for general attitudes, $t(365)=-5.08, p<.001$, Cohen's $d=.54$, and sexual interest, $t(365)=6.06, p<.001$, Cohen's $d=.60$. Table 3 shows the mean differences for gender across all included variables. Women had greater risk knowledge. Men had greater sexual interest and were less conservative in their general attitudes. Though not statistically significant with the adjustment to alpha levels, women were more permissive than men on age-specific attitudes. Men and women did not differ significantly in the frequency of sexual activity or in their overall sexual satisfaction.

Race/ethnicity. A between-subjects, one-way ANOVA was used to investigate mean differences on sexuality scales by race. The same scales were investigated as those for gender 
differences, thus once again, alpha values were adjusted. Table 4 displays the test statistics for each group comparison. Significant differences were found for risk knowledge $(F(2,364)=$ $\left.5.24, p=.006, \eta^{2}=.03\right)$ and ASKAS attitudes $\left(F(2,364)=8.45, p<.001, \eta^{2}=.05\right)$. Post hoc tests revealed that Whites $(M=6.69, S D=1.72)$ held greater risk knowledge than Hispanic Americans $(M=5.90, S D=1.98)$, but were not significantly different from African Americans $(M=6.47, S D=1.74)$. For age-specific attitudes, Hispanic Americans $(M=82.97, S D=22.03)$ had significantly more conservative attitudes than either Whites $(M=70.85, S D=20.90)$ or African Americans $(M=74.13, S D=22.09)$. No significant differences were found in frequency of sexual activity or sexual satisfaction.

\section{Model Development}

In order to develop the most parsimonious model, bivariate correlations were examined. Because the two separate interest measures correlated highly with one another $(r=.68)$, they were combined into a single measure of sexual interest $(\alpha=.79)$. Both sexual attitude measures were retained in the structural model because conceptually they represent distinct attitudinal components. The moderate correlation between the measures $(r=.28)$ supports this decision. Finally, the two knowledge measures, risk/contraceptive knowledge and age-specific knowledge, were evaluated for inclusion. Risk knowledge did not demonstrate a compelling pattern of associations with other elements of the model except ASKAS attitudes $(r<.20)$ and was excluded from the model. Age-specific knowledge as measured by the ASKAS subscale was used as the observed knowledge variable. Because gender was significantly correlated to several elements of the structural model, it could be included for hypothesis testing.

Although post-hoc power analyses at alpha levels of .95 indicated adequate power to detect small to medium effect sizes, the data were underpowered to test the research question 
pertaining to three-group, racial differences within a structural model with 23 estimated parameters (smallest $n=73$ ). The standard recommendation is between 10 and 20 participants per parameter (Kline, 1998). Given the lack of racial differences detailed in the preliminary analyses above, if differences exist, greater power would be necessary to detect the small effects of race/ethnicity on the variables represented in this model. Further, partial correlations among sexuality components and the sexual well-being measures with race factored out did not impact the magnitude of the correlation coefficients (see Table B1 in Appendix B for partial correlations). Due to insufficient power and evidence, the research question to investigate the influence of race on a model of middle-aged and late life sexuality was abandoned in the current study.

The observed variables expected to comprise the latent construct of sexual well-being were evaluated against the standard that correlations between these measures should have greater magnitude than with other observed or latent constructs (Byrne, 2001). The strong correlations ( $r$ $=.44-.93$ ) among sexual frequency, overall satisfaction and the 3-item satisfaction scale suggest preliminarily that the measurement model will be adequate and stable.

All analyses were performed with AMOS version 18 (Arbuckle, 1995). The overall fit of the model was assessed using the Adjusted Goodness-of-Fit Index (AGFI) and the Tucker Lewis Index (TLI); these measures indicate good model fit at .95 or greater (Byrne, 2001). The Root Mean Square Error Approximation (RMSEA) was also considered along with confidence intervals to determine fit. Byrne suggests a threshold of .08 to .05 for adequate fit, with less than .05 indicating good model fit. Maximum likelihood estimates (MLE) for each path were tested for statistical significance using the Critical Ratio (CR=MLE/Standard Error of MLE). Like all z- 
scores, CRs greater than 1.96 are interpreted as statistically significant at the $p<.05$ level (Arbuckle).

\section{Hypothesis Testing}

Hypothesis 1-Measurement model. The structural model and measurement model were assessed simultaneously. The top portion of Table 5 shows the maximum likelihood estimates, standardized regression weights, standard errors, and critical ratios. As can be noted from the critical ratios (all greater than 1.96), all observed measures mapped onto the sexual well-being construct.

Structural model. The overall model fit statistics indicate an acceptable overall fit, $\chi^{2}(12$, $N=367)=17.47, p=.13 ; \mathrm{AGFI}=.965 ; \mathrm{TLI}=.992 ;$ and RMSEA $=.035, R^{2}=.315$. There was one non-significant path that could improve fit (gender to knowledge, $\mathrm{MLE}=.02, \mathrm{CR}=.46$ ). Given no a priori hypotheses about whether knowledge differs by gender, this path was removed. The model was re-analyzed and fit of the model improved slightly, $\chi^{2}(13, N=367)=$ $17.69, p=.17 ; \mathrm{AGFI}=.967 ; \mathrm{TLI}=.994 ;$ and RMSEA $=.031$. The modification indices did not suggest any other paths to improve model fit. The structural model accounted for $33.1 \%$ of the variance in sexual well-being. Figure 2 illustrates the structural model with standardized betas displayed for each path.

Inspection of the standardized regression weights indicated support for all of the individual, hypothesized paths. Sexual interest had the clearly strongest path to sexual well-being $(\mathrm{MLE}=.53, \mathrm{CR}=10.83)$ followed by general sexual attitudes $(\mathrm{MLE}=.17, \mathrm{CR}=3.66)$. The weakest paths were between the age-specific, observed ASKAS subscales and sexual well-being, nearing the $1.96 \mathrm{CR}$ cutoff. The bottom of Table 5 provides the relevant statistics for these paths. 
Hypothesis 2. With regard to Hypothesis 2, the paths between gender and sexual interest, general sexual attitudes, and age-specific sexual attitudes were all significant. The strongest path was between gender and interest (MLE $=-.31, \mathrm{CR}=-6.26$ ) with men demonstrating greater sexual interest. The paths from gender to general sexual attitudes (MLE $=.26, \mathrm{CR}=5.09$ ) as well as age-specific attitudes (MLE $=-.11, \mathrm{CR}=-2.24$ ) were also significant. Interestingly, the paths between gender and the two attitudinal measures indicated an inverse relationship, wherein men were more permissive generally, but more conservative with regard to age-specific attitudes than women.

To compare the models by gender, gender was first removed from the structural model. The overall model fit without the influence of gender was still adequate, $\chi^{2}(18, N=367)=$ 23.02, $p=.19 ; \mathrm{AGFI}=.946 ; \mathrm{TLI}=.993 ;$ and $\mathrm{RMSEA}=.028$. Examination of the critical ratio differences between parameters in the male and female models did not reveal significant differences $(\mathrm{CR}$ differences < 1.96). Inspection, however, of the standardized regression paths (see Tables 6 and 7) indicated that the selected parameters may be operating differently for men and women in accounting for variance in sexual well-being.

For men, $25.9 \%$ of the variance was being accounted for with sexual interest (MLE $=.46$, $\mathrm{CR}=6.16)$ and general sexual attitudes (MLE $=.19, \mathrm{CR}=2.82)$ as the strongest paths. For women, the structural model accounted for over $40 \%$ of the variance $(41.3 \%)$ in sexual wellbeing. Again, the path between sexual interest and sexual well-being was the strongest (MLE = $.60, \mathrm{CR}=9.05$ ), but for women, age-specific sexual knowledge was also a significant path (MLE $=.13, \mathrm{CR}=2.07)$. While the differences between men and women on these parameters were not enough to reach statistical significance, beyond interest, there are clear differences in which variables impact sexual well-being. Therefore, as hypothesized, mean differences exist between 
men and women on sexuality variables, but the pattern of associations indicates that the same model can be used for either gender.

\section{Redefining Successful Aging: Where Does Sexual Well-being Fit?}

Hypothesis 3 was tested by entering the sexual well-being measures from the previous analyses (overall satisfaction, component satisfaction, and reported frequency in the past year) and multiple measures of physical and psychological well-being into an exploratory factor analysis (EFA) using SPSS version 18. Inspections of the bivariate correlations among included measures were well above the prescribed .30 cutoff (Tabachnick \& Fidell, 2013). Further, the Kaiser-Meyer-Olkin value was .797, which exceeded the suggested cutoff of .60 and Bartlett's Test of Sphericity was significant $(p<.001)$. These preliminary analyses established that factor analysis was appropriate given the data.

Using a principal components extraction, three components were extracted as predicted, explaining a total of $79.58 \%$ of the variance. The first component accounted for $44.26 \%$ of the variance, with the second component contributing $20.65 \%$ and the last component, $14.67 \%$. Inspection of the scree plot confirmed retaining these three components. The rotated solution demonstrated a simple structure with each component represented by multiple strong loadings and each scale loading strongly on only one component (Thurstone, 1947). Table 8 contains the pattern matrix coefficients for the three-component solution.

The interpretation of the three components was consistent with what had been hypothesized: sexual well-being exists as a distinct and separate entity from both physical and mental well-being. These three components are moderately correlated with the strongest relation between mental and physical health $(r=.36)$, followed by mental health and sexual well-being $(r$ 
$=-.31)$ and finally physical health and sexual well-being $(r=-.25)$. Similar results were obtained through a confirmatory approach in AMOS; these results can be found in Appendix C.

\section{Discussion}

To understand sexuality at any point in the lifespan, a multidimensional approach is necessary (DeLamater \& Friedrich, 2002; Dennerstein, et al., 2009; Kinsey et al., 1948; Parker, 2009; Waite et al., 2009). The current investigation followed this approach by investigating sexuality in a diverse sample of middle-aged and older adults, and assessing the extent to which sexual interest, attitudes, and knowledge influences sexual well-being. Furthermore, this study sought to move beyond mere description of sexuality, and rather, identify possible mechanisms to explain individual differences in sexual well-being.

\section{A More Comprehensive Model of Sexual Well-Being}

The data in the current study support the hypothesis that sexual well-being is a multidimensional construct related to sexual interest, attitudes, and knowledge. Multiple measures of sexual satisfaction were included to represent sexual well-being. As in other investigations (i.e., Laumann et al., 2006), the different facets of satisfaction (physical, emotional, etc.) related strongly ( $r$ greater than .65$)$ with one another. When combined, this newly-created scale strongly related with a single-item of overall satisfaction, suggesting that an individual's global appraisal of sexual satisfaction is influenced by these individual elements. Taken together with frequency (of which $72 \%$ reported being sexually active within the last year), these variables represented the latent construct of sexual well-being.

In combining a behavioral component (frequency) with subjective appraisal (satisfaction), the current study was able to more comprehensively fit a model to sexual wellbeing, specifically for those who were sexually active. Woloski-Wruble and colleagues (2010) 
conceptualized a model of sexual health in middle-aged and older adult Israel women, which included physical, mental, emotional, and social components of sexuality. Unfortunately, however, their small sample $(N=127)$ limited the sophistication of their analyses, resorting to bivariate associations. Defining sexual well-being on these particular dimensions allows researchers to recognize that there are multiple paths to sexual well-being. For instance, sexual satisfaction has been shown to remain relatively stable despite declines in sexual activity and functioning (Thompson et al., 2011). Furthermore, this subjective appraisal of sexual well-being remained positively related to quality of life and subjective measures of successful aging in a sample of women ages 60-89 years.

While the hypothesized model held for the sample in predicting sexual well-being, the paths varied in explanatory strength. Sexual interest, measured through a combination of selfreported level of sexual desire, importance of sex, and time dedicated to thinking about sex, was the strongest indicator of sexual well-being. This finding is consistent with other studies that have found a strong link between self-reported interest and maintaining sexual activity into late life (DeLamater \& Karraker, 2009; Moore, 2010).

Other studies have suggested that sexual interest is susceptible to a variety of personal and contextual elements, such as health and availability of a partner (Beckman et al., 2008; DeLamater \& Karraker; Dennerstein et al., 2009). Therefore, if sexual interest is reduced by an event outside of the individual's control, it could lead to less sexual well-being. Research suggests, however, that middle-aged and older adults may adapt to these circumstances to protect their sense of sexual well-being by actively devaluing sexual activity as an important component of later life and compensating with other activities (AARP, 1999). 
General sexual attitudes also contributed significantly to the sexual well-being model. Studies have indicated that those with more permissive sexual attitudes may engage in sexual activity into later life (Steinke, 1994; Wang et al., 2008). In this study, the inverse was found, such that those expressing more conservative, general sexual attitudes had greater sexual wellbeing. Given that nearly $65 \%$ of the sample was married or cohabitating, these participants may hold more traditional opinions on the sanctity of their relationships with regard to cheating and casual sex, even though the questions advised individuals to think broadly about relationships rather than focusing on their own. In situations of divorce (an increasingly common demographic category, especially among middle-aged and younger adults) or widowhood (common among older adult females), being more open with regard to sexual attitudes may be a compensatory mechanism given their situation.

In the current study, age-specific attitudes and knowledge also corresponded significantly to sexual well-being, although these associations were weaker. Specifically, permissive attitudes about older-adult sexuality and greater knowledge corresponded to enhanced sexual well-being. Given the demographic profile of the sample (a high proportion of middle-aged participants and young-old adults), the impact of these two measures may be weaker than expected simply because these individuals may not yet identify as older adults. The biggest predictors of identifying as an "older adult" tend to be chronological age and declining health (Logan, Warde, \& Spitze, 1992). Being divorced or widowed has also been shown to associate with labeling one's self as old versus middle-aged.

The hypothesized model explained close to one-third of the variance in sexual well-being in a middle-aged and young-old sample. Other individual and contextual level predictors, such as marital status (Beckman et al., 2008; DeLamater \& Karraker, 2009; Dennerstein et al., 2009; 
Skultety, 2007), duration of the relationship (DeLamater \& Karraker, 2009), and physical and mental health status (DeLamater \& Friedrich, 2002; DeLamater \& Karraker; Lindau et al., 2007; Matthias et al., 1997) might be useful alongside these psychological and cognitive variables to explain additional variance. These findings do highlight the value of considering variables such as interest, attitudes, and knowledge in understanding sexuality beyond the childbearing years.

\section{Gender}

The second hypothesis assessed gender differences in sexual well-being. Mean difference tests indicated common patterns of gender differences (i.e., Bancroft, 2007; Bonds-Raacke \& Raacke, 2011; Dennerstein et al., 2009; Mosher \& Danoff-Burg, 2005) in sexuality measures, specifically with men showing greater sexual interest and holding more open, general attitudes about sexual relationships. With gender in the structural model, it was possible to see the influence of these differences with gender relating to all but age-specific sexual knowledge, and in turn, the sexuality components of attitudes, knowledge, and interest all significantly relating to sexual well-being.

But when comparing the model between genders, a slightly different story emerged with this same combination of variables accounting for different amounts of variance in men and women's sexual wellness. For men, it appears that interest and general sexual attitudes account for a little more than one-quarter of sexual well-being, yet neither age-specific measure (attitudes or knowledge) was significant. More variance was accounted for in the model of women's sexual well-being with sexual interest contributing the most, followed only by age-specific sexual knowledge. It is of interest to note that while these models were obviously functioning differently for men and women, tests of the critical ratio differences did not indicate men and women differed significantly from one another, suggesting these differences are small. 
Taken together, these findings indicate that while variables such as interest, attitudes, and knowledge are important in understanding both men's and women's sexual well-being, certain aspects may be more central to one gender versus the other. Furthermore, these variations in what equates sexual well-being for men and women may stem from differences in sexual socialization that commence early in the lifespan. Because the model focused on the socialized aspects of sexuality rather than solely biological or physiological variables, these findings suggests that middle-aged and older adult men and women may require different intervention messages aimed at improving sexual well-being. A longitudinal study incorporating both biological and psychological variables would be necessary to understand the effects of differential changes by gender in predicting future sexual well-being.

Future research in this area will want to address and probe deeper into these gender differences. First, women were marginally more permissive in their age-specific attitudes than men $(p=.02)$. While not an important indicator of sexual well-being for either sex (possibly for reasons described previously), this may indicate that women possess a greater openness and understanding of older adult sexual needs. Because women are commonly in the caregiver role for older adult parents and have a more communal personality (Mosher \& Danoff-Burg, 2005), their actual experiences with older adults may increase their sensitivity to their own and their partner's late life sexual well-being.

Despite more receptive attitudes towards late life sexuality and needs, women did not differ from men in their knowledge of older adult sexual function. However, age-specific sexual knowledge was a significant predictor of women's sexual well-being. Accurate knowledge about the biological changes in late life may be more salient and personally meaningful to women who are up against the stereotype that women lose their sense of sexual selfhood following 
menopause (Rheaume \& Mitty, 2008). Therefore, awareness of what their bodies are actually capable of makes the decision to remain sexually active within a woman's control.

Finally, men and women differed significantly on their risk knowledge though this variable was not included in the model of sexual well-being. Women demonstrated greater knowledge of contraception and potential sexual risks. Greater knowledge does not necessarily equal safer practices, but this finding may be an important consideration in how safe-sex decisions are made between partners in middle and late adulthood, especially if these adults are forming new sexual relationships following divorce or widowhood. Research indicates that men are more likely to engage in these new relationships later in life (DeLamater \& Friedrich, 2002); with lower risk knowledge, men may be driving the climbing rates of STI contraction in the older adult population. More research is necessary.

\section{Race}

The current study is one of the few recent investigations of sexuality in a middle-aged and older adult population to use a racially and ethnically diverse sample. While the full model could not be compared across these demographic groups, mean differences were evaluated between Whites, African Americans, and Hispanic Americans. Mean differences were found for risk knowledge such that Hispanic Americans demonstrated the lowest levels. This finding may be reflective of cultural differences in sexual socialization and general communication about sexuality (Adams \& Williams, 2011; Wilson, Dalberth, Koo, \& Gard, 2010). No racial/ethnic differences were found on the observed measures of sexual well-being (frequency or sexual satisfaction).

A small effect of race was found on age-specific attitudes with Hispanic Americans reporting more conservative sexual attitudes than Whites or African Americans though no 
differences were found on the general, sexual attitudes measure. This finding is unexpected and requires further investigation to understand the cultural and subcultural forces that may be influencing these findings. It is consistent with Fugere and colleagues (2008) suggestion that African Americans and Whites may be more similar in their sexual attitudes than with Hispanic or Asian Americans because African Americans represent a subset of the majority culture rather than an immigrant, minority culture that becomes acculturated to majority values.

\section{Sexual Well-Being as a Distinct Pillar of Successful Aging}

Debate continues about what components are essential to a successful aging model (Blazer, 2006; Lang et al., 2011; Rowe \& Kahn, 1997). Generally, models include components of physical and mental well-being. While not explicitly investigated from a successful aging model, it has been assumed that sexuality in adulthood falls within the physical realm seeing as it is consistently investigated with regard to the biological and physiological declines and dysfunction. But in conceptualizing sexuality as a multi-dimensional construct encompassing not only physical, but cognitive and social elements as well, this study hypothesized that sexuality, though related to physical and psychological well-being, could and should be considered distinctly. This hypothesis was confirmed.

This finding supports the necessity of incorporating a successful aging theoretical foundation in future studies of sexuality. Rather than approaching sexuality as a strictly physical, or for that matter, a strictly psychological construct, it is better to consider sexuality as aligned with these other pillars of successful aging and as a distinct influence on an aging individual's well being. Sexual dysfunction and biological changes may not automatically signal unhappiness or loss of sexual identity as previously suggested. As with all change, some individuals will learn 
to adjust to these changes to maintain their functioning, while others may compensate for losses (Baltes, 1987).

Further, in approaching sexual well-being objectively (sexual frequency behavior) and subjectively (self-reported sexual satisfaction), the approach taken in this study has improved upon one of the largest criticisms of the successful aging literature. Dillaway and Byrnes (2009) suggest that much of the rhetoric surrounding the idea of successful aging fails to be sensitive to individual needs and may actually contribute to ageism by suggesting that if an older adult is no longer capable of engaging in something deemed essential to a successful aging model that they must be failing to thrive. In defining sexual well-being as more than just frequent or continued engagement in sexual activity and incorporating a subjective element, this study allowed for multiple ways to achieve sexual wellness.

\section{Limitations \& Progress}

The current study is limited in generalizability. While a research question was posed to address racial/ethnic differences in sexuality, the sample was underpowered to investigate these differences within a complex, conceptual model. Other limitations of generalizability include the exclusion of sexual minorities and the population from which the sample was drawn. The source or underlying causal mechanisms remain uninvestigated without longitudinal data. Finally, threats to construct validity must be considered with the measures used to tap the sexuality constructs believed to be represented in the study.

Race/ethnicity. Previous research, both empirically grounded and speculative, has suggested why race/ethnicity may matter in investigating sexuality development across the lifespan (i.e., Bogue, 2010; Fugere et al., 2008; Huang et al., 2009). In the current study, few racial/ethnic differences emerged in preliminary analyses. The discrepancy between the present 
study and others may be due to investigating racial differences across rather than within gender as suggested from the differences found in Huang and colleagues' (2009) sample of all women. The lack of racial/ethnic differences may also stem from how this variable was categorized. Given the growing diversity within the United States and the expansion of the immigrant population, it is now common to separate race (white v. non-white) from ethnicity when capturing these demographics. Further, the term Hispanic is increasing being subdivided into regional ethnicities so as to capture cultural differences that exist within each (Pew Hispanic Center, 2012).

Another limitation with regard to race/ethnicity is that the present study opted to focus solely on Whites, African Americans, and Hispanic Americans, excluding those identifying as anything other. Of those excluded, 12 identified as bi-racial, multi-racial, or other, but no attempt was made to capture what racial/ethnic groups these individuals represented. If racial/ethnic differences do exist with respect to sexuality components, this group may represent a unique combination of influences.

Future research will want to expand the scope of investigating racial/ethnic differences in middle to late life sexuality to include these less studied populations. More recently, studies have been conducted with Asian samples (i.e., Ford \& Chamratrithirong, 2012; Moore, 2010; Shea, 2011). but once again, regional differences may be important to consider, especially when investigating more socially-influenced elements of sexuality, such as attitudes and knowledge. It may also be important to consider the impact of acculturation or length of residency for minorities who are not native to the country where the study is being conducted.

Heterosexist bias. One of the outstanding shortcomings of the aging and sexuality literature is the lack of information on sexual minorities. In this study, participants were asked to 
self-identify using a revised version of the Kinsey scale (Kinsey et al., 1948). Only 29 individuals self-identified as bisexual or predominately homosexual. These individuals were excluded because preliminary analyses on this subset suggested some differences on the variables of interest (see Appendix D). With such a small sample, it was not plausible to explore these differences fully.

Small sample size is a common problem in the sexuality and aging literature. A recent report released by Gallup (2012) indicated that $3.4 \%$ of the United States population selfidentifies as LGBT. If this statistic is broken into specific age ranges, only $2.6 \%$ of adults age 50 64 years and $1.9 \%$ of adults over the age of 65 identify as such. Future research must actively focus on collecting representative samples of middle-aged and older adult LGBT participants to model sexual well-being in this population. Some strides are being made, but these studies are generally focused on at-risk populations such as those living with HIV (i.e., Brennan, Emlet, \& Eady, 2011).

Online sampling. There are many benefits to using online samples, especially for sexuality research. The methodology is efficient, easy for participants to follow, and may increase the perception of anonymity when answering questions about sensitive topics (AlTayyib et al., 2002). But there are also risks involved with recruiting online, especially for older adult samples. According to the Pew Center (2012), adults over the age of 50 represent the fastest growing population with regard to social media use and for the first time ever, over half of the individuals over the age of 65 report using the internet. Internet access, however, does not mean these individuals are technologically savvy.

Also, those frequenting websites such as Mechanical Turk may represent a special subset of the middle-aged and older adult population. For instance, common gender, age, and racial 
differences in health and well-being were not found in the present study. While recent studies comparing data collected through Mechanical Turk and other sources (online and in-person) have suggested more similarity than differences both demographically and psychometrically (see Buhrmester, Kwang, \& Gosling, 2011; Johnson \& Borden, 2012), online samples generally tend to have higher levels of education (Gosling, Vazire, Srivastava, \& John, 2004). Education is often used as a proxy variable for socioeconomic status and has been shown to influence perceived health (i.e., Ross \& Mirowsky, 1999), which may be accounting for some of the differences found in the current study in comparison to previously published differences in health and well-being based on age, race, and gender. According to recent census data, $48 \%$ of individuals over the age of 55 have attained no more than a high school diploma or GED (United States Census Bureau, 2012). In the present study, only $20.9 \%$ did not pursue post-secondary options.

Within this particular online sample, $37 \%$ of cases were excluded because individuals did not meet the study requirements, did not complete at least $50 \%$ of the survey, or failed multiple, validity checks. Another concern is that participants using the internet to complete knowledgebased assessments may be more tempted to use web browsers to locate answers. As researchers, it is important to be conscious of the risks to validity no matter what mode of data collection is used. In doing so, it is possible to build assessments to protect participants' rights as well as researcher interests.

Cross-sectional data. Caution is needed when assessing causal relationships within this body of work. Though the model hypothesized and supported within this study suggests that interest, attitudes, and knowledge influence sexual well-being, a bi-directional relationship is probably a more realistic depiction of these relationships. In order to investigate these 
relationships as such as well as the influence of time, longitudinal data informed by crosssectional research, such as the present study, is important. However, given the impact of history and time, even with longitudinal data these findings may not be generalizable to future generations.

Measures. Many measures are used throughout the literature in an attempt to gain a more accurate and robust picture of sexuality beyond the childbearing years. There is a lack of attention, however, to the validity of these measures within aging populations. Unfortunately, this study does not escape this criticism. The Finnish KISS sexual risk assessment (Part et al., 2008) was initially designed for use in an adolescent population; whether this measure was appropriate to use within this investigation to gain the same insights into risk knowledge is unknown. Scale scores may be indicating something about the sample's sexual risk knowledge, but without other measures to cross-validate or qualitative follow-ups this is a risky assumption. The current findings do establish that middle-aged and older adults may differ as a function of their gender and racial/ethnic backgrounds with respect to sexual risks, highlighting which subpopulations may be at greater risk.

Additionally, the ASKAS scale which has been previously validated with middle-aged and older adult samples (see White, 1982) may be outdated. With the development and advertisement of sexual dysfunction remedies, access to knowledge about this medical issue has increased substantially. Whether greater exposure translates to greater knowledge remains to be seen. Additionally, sexual attitudes have become increasingly permissive since the sexual revolution, though research has suggested that the degree of acceptance of sexual behaviors and relationships may differ depending on the nature of the topic (Ahrold \& Meston, 2010). Despite these possible criticisms, the current sample did score similarly to published means from the 
original validation studies which suggests that this increased openness may not extend to sexuality expressed among middle-aged and older adults in this sample.

\section{Conclusion}

This study was designed to investigate a multidimensional model of sexual well-being in a middle-aged and older adult sample. Sexual well-being was conceptualized to incorporate both subjective and objective measures and was shown to be most influenced by sexual interest in the present study. Sexual attitudes (general and age-specific) and age-specific sexuality knowledge also influenced sexual well-being, but to a lesser extent. The model was a departure from the more common approach of considering only sexual dysfunction as an indicator of sexual wellness in mid- to late-life. While men and women do differ on aspects of the model (sexual interest and attitudes), they do not differ significantly in sexual well-being as measured in this investigation. These findings are consistent with previous work and suggest that men and women may just differ in what is considered important to their sexual well-being.

This study was also the first to attempt integrating the influences of race/ethnicity within a more complex model of sexuality beyond the childbearing years. Preliminary analyses revealed more similarity than difference between Whites, African Americans, and Hispanic Americans. But given limited generalizability of the sample (i.e., online-only sample, limited group comparisons, young average age, and mainly married/cohabitating), these findings need to be replicated with other racially/ethnically-diverse samples. Specifically, the intersection of race/ethnicity and gender on sexual risk knowledge deserves greater attention, especially as practitioners seek to target interventions at sexually-active, middle-aged and older adult populations at greatest risk of contracting and spreading STIs. 
Finally, many of the approaches to sexuality research in aging populations have been descriptive and without theoretical direction. The present study demonstrated how sexual wellbeing fits as a component of successful or optimal aging that is related to, but distinct from both physical and psychological well-being. This result highlights the importance of being sensitive and aware of the influence that sexual wellness can have on an aging individual, independent of the effects of other, more commonly targeted components of well being. It suggests that the common practice of simply dismissing matters of sexuality in this population may hinder successful aging. Future research on sexuality in middle-aged and older adults needs to first acknowledge that sexuality continues to change and develop beyond the childbearing years. Next, the development of sexuality should be evaluated alongside, but separate from changes in physical and psychological functioning. Finally, acceptance and tolerance need to be promoted by educating society on the very real and powerful influence sexual well-being has on an individual, regardless of age. 


\section{References}

AARP (1999). AARP/Modern maturity sexuality study. Retrieved from http://assets.aarp.org/rgcenter/health/mmsexsurvey.pdf

Adams, H.L., \& Williams, L.R. (2011). What they wish they would have known: Support for comprehensive sexual education from Mexican American and White adolescents' dating and sexual desires. Children \& Youth Services Review, 33, 1875-1885. doi:

10.1016/j.childyouth.2011.05.013

Ahrold, T.K., \& Meston, C.M. (2010). Ethnic differences in sexual attitudes of US college students: Gender, acculturation, \& religiosity. Archives of Sexual Behavior, 39, 190-202. doi: $10.1007 / \mathrm{s} 10508-008-9406-1$

Andersen, H.H., Mühlbacher, A., Nübling, M., Schupp, J., \& Wagner, G.G. (2007). Computation of standard values for physical and mental health scale scores using the SOEP version of SF-12v2. Journal of Applied Social Science Studies, 127, 171-182.

Arbuckle, J.L. (1995). Amos User's Guide. Chicago, IL: Smallwaters.

Al-Tayyib, A.A., Rogers, S.M., Gribble, J.N., Villarroel, M., \& Turner, C. F. (2002). Effect of low medical literacy on health survey measures. American Journal of Public Health, 92, $1478-1481$.

Allen, R.S., Petro, K.N., \& Phillips, L.L. (2009). Factors influencing young adults' attitudes and knowledge of late-life sexuality among older women. Aging \& Mental Health, 13, 238245. doi: 10.1080/13607860802342243

Araujo, A.B., Mohr, B.A., \& McKinlay, J.B. (2004). Changes in sexual function in middle-aged and older men: Longitudinal data from the Massachusetts Male Aging Study. Journal of the American Geriatrics Society, 52, 1502-1509. 
Baldwin, J.D., \& Baldwin, J.I. (1997). Gender differences in sexual interest. Archives of Sexual Behavior, 26(2), 181-210.

Baltes, P.B. (1987). Theoretical propositions of life-span developmental psychology: On the dynamics between growth and decline. Developmental Psychology, 23(5), 611-626.

Bancroft, J.H. (2007). Sex and Aging. The New England Journal of Medicine, 357, 820-822.

Becker, L.A. (2000). Effect Size Calculators. In University of Colorado-Colorado Springs College of Letters, Arts, and Sciences. Retrieved December 21, 2012, from http://www.uccs.edu/lbecker/index.html.

Beckman, N., Waern, M., Gustafson, D., \& Skoog, I. (2008). Secular trends in self-reported sexual activity and satisfaction in Swedish 70 year olds: Cross sectional survey of four populations, 1971-2001. BMJ. Advance online publication. doi: 10.1136/bmj.a279

Bersamin, M., Todd, M., \& Remer, L. (2011). Does distance matter? Access to family planning clinics and adolescent sexual behaviors. Maternal and Child Health Journal, 15, 652659. doi: 10.1007/s10995-010-0618-3

Blazer, D.G. (2006). Successful aging. American Journal of Geriatric Psychiatry, 13, 2-5.

Brennan, D.J., Emlet, C.A., \& Eady, A. (2011). HIV, sexual health, and psychosocial issues among older adults living with HIV in North America. Ageing International, 36(3), 313333. doi: 10.1007/s12126-011-9111-6

Bogue, D.J. (2010). Contraception, attitude-practice, and fertility differentials among US Hispanic, African-American, and white women. Journal of Population Research, 27, 275-292. doi: 10.1007/s12546-011-9052-7 
Bonds-Raacke, J.M., \& Raacke, J. (2011). Examining the relationship between degree of religiousness and attitudes toward elderly activity in undergraduate college students. College Student Journal, 45, 134-142.

Buhrmester, M., Kwang, T., \& Gosling, S.D. (2011). Amazon's Mechanical Turk: A new source of inexpensive, yet high-quality, data? Perspectives on Psychological Science, 6(1), 3-5. doi: $10.1177 / 1745691610393980$

Byrne, B.M. (2001). Structural Equation Modeling with AMOS: Basic Concepts, Applications, and Programming. Mahwah, NJ: Lawrence Erlbaum Associates.

Carstensen, L.L., Pasupathi, M., Mayr, U., \& Nesselroade, J.R. (2000). Emotional experience in everyday life across the adult life span. Journal of Personality \& Social Psychology, 79, 644-655. doi: 10.1037//O022-3 514.79.4.64

Cohen, J. (1992). A power primer. Psychological Bulletin, 112(1), 155-159.

Cohler, B.J., \& Galatzer-Levy, R.M. (2000). The course of gay and lesbian lives: Social and psychoanalytic perspectives. Chicago, IL: University of Chicago Press.

DeLamater, J., \& Friedrich, W.N. (2002). Human sexual development. Journal of Sex Research, 39, 10-14.

DeLamater, J., \& Karraker, A. (2009). Sexual functioning in older adults. Current Psychiatry Reports, 11, 6-11.

Dennerstein, L., Hayes, R., Sand, M., \& Lehert, P. (2009). Attitudes toward and frequency of partner interactions among women reporting decreased sexual desire. Journal of Sexual Medicine, 6, 1668-1673. doi: 10.1111/j.1743-6109.2009.01274.x

Diener, E. (1984). Subjective well-being. Psychological Bulletin, 95(3), 542-575.

Diener, E., Suh, E.M., Lucas, R.E., \& Smith, H.L. (1999). Subjective well-being: Three decades of progress. Psychological Bulletin, 125(2), 276-302. 
Eisenberg, M.L., Shindel, A.W., Smith, J.F., Breyer, B.N., \& Lipshultz, L.I. (2010).

Socioeconomic, anthropomorphic, and demographic predictors of adult sexual activity in the United States: Data from the National Survey of Family Growth. Journal of Sexual Medicine, 7, 50-58. doi: 10.1111/j.1743-6109.2009.01522.x

Emmers-Sommer, T.M., Nebel, S., Allison, M., Cannella, M.L., Cartmill, D., Ewing, S., ... Wojtaszek, B. (2009). Patient-provider communication about sexual health: The relationship with gender, age, gender-stereotypical beliefs, and perceptions of communication inappropriateness. Sex Roles, 60, 669-681. doi: 10.1007/s11199-008$9577-1$

Faul, F., Erdfelder, E., Lang, A.-G., \& Buchner, A. (2007). G*Power 3: A flexible statistical power analysis program for the social, behavioral, and biomedical sciences. Behavior Research Methods, 39, 175-191.

Flynn, K.E., Smith, M.A., \& Freese, J. (2006). When do older adults turn to the Internet for health information? Findings from the Wisconsin Longitudinal Study. Journal of General Internal Medicine, 21, 1295-1301. doi: 10.1111/j.1525-1497.2006.00622.x

Ford, K., \& Chamratrithirong, A. (2012). Midlife sexuality among Thai adults: Adjustment to aging in the Thai family context. Sexuality \& Culture, 16, 158-171. doi: 10.1007/s12119011-9115-0

Fugere, M.A., Escoto, C., Cousins, A.J., Riggs, M.L., \& Haerich, P. (2008). Sexual attitudes and double standards: A literature review focusing on participant gender and ethnic background. Sexuality \& Culture, 12, 169-182. doi: 10.1007/s12119-008-9029-7 
Galinha, I.C., \& Pais-Ribeiro, J.L. (2008). The structure and stability of subjective well-being: A structure equation modeling analysis. Applied Research Quality Life, 3, 293-314. doi: 10.1007/s11482-009-9063-0

Gates, G.J., \& Newport, F. (2012). Special report: 3.4\% of U.S. adults identify as LGBT. Retrieved from Gallup Politics website: http://www.gallup.com/poll/158066/specialreport-adults-identify-lgbt.aspx

Gosling, S.D., Vazire, S., Srivastava, S., \& John, O.P. (2004). Should we trust web-based studies? A comparative analysis of six preconceptions about Internet questionnaires. American Psychologist, 59(2), 93-104. doi: 10.1037/0003-066X.59.2.93

Gott, C.M. (2001). Sexual activity and risk-taking in later life. Health \& Social Care in the Community, 9(2), 72-78.

Guan, J. (2004). Correlates of spouse relationship with sexual attitude, interest, and activity among Chinese elderly. Sexuality and Culture, 8(1), 104-131.

Harrod, M. (2011). "I have to keep going:" Why some older adults are using the Internet for health information. Ageing International, 36, 283-294. doi: 10.1007/s12126-010-9090-z

Henderson, A.W., Lehavot, K., \& Simoni, J.M. (2009). Ecological models of sexual satisfaction among lesbian/bisexual and heterosexual women. Archives of Sexual Behavior, 38, 5065. doi: 10.1007/s10508-008-9384-3

Hillman, J. (2011). A call for an integrated biopsychosocial model to address fundamental disconnects in an emergent field: An introduction to the special issue on "Sexuality and Aging.” Ageing International, 36, 303-312. doi: 10.1007/s12126-011-9122-3

Hillman, J.L., \& Stricker, G. (1994). A linkage of knowledge and attitudes toward elderly sexuality: Not necessarily a uniform relationship. The Gerontologist, 34, 256-260. 
Howell, D. C. (2009). Statistical methods for psychology (7th.ed.). Belmont, CA: Duxbury Press.

Huang, A.J., Subak, L.L., Thom, D.H., Van Den Eeden, S.K., Ragins, A.I., Kuppermann, M.,...Brown, J.S. (2009). Sexual function and aging in racially and ethnically diverse women. Journal of American Geriatrics Society, 57, 1362-1368. doi: 10.1111/j.15325415.2009.02353.x

Hyde, J.S. (2005). The gender similarities hypothesis. American Psychologist, 60(6), 581-592. doi:10.1037/0003-066X.60.6.581

Jenkinson, C., Chandola, T., Coulter, A., \& Bruster, S. (2001). An assessment of the construct validity of the SF-12 summary scores across ethnic groups. Journal of Public Health Medicine, 23(3), 187-194.

Johnson, D.R., \& Borden, L.A. (2012). Participants at your fingertips: Using Amazon's Mechanical Turk to increase student-faculty collaborative research. Teaching of Psychology, 39(4), 245-251. doi: 10.1177/0098628312456615

Jones, K.E., da Silva, A.M., \& Soloski, K.L. (2011). Sexological systems theory: an ecological model and assessment approach for sex therapy. Sexual and Relationship Therapy, 26(2), 127-144. doi: 10.1080/14681994.2011.574688

Karlamangla, A., Tinetti, M., Guralnik, J., Studenskil, S., Wetle, T., \& Reuben, D. (2007). Comorbidity in older adults: Nosology of impairment, diseases, and conditions. Journals of Gerontology: Biological Sciences/Medical Sciences, 62, 296-300.

Kinsey, A.C., Pomeroy, W.B., \& Martin, C.E. (1948). Sexual behavior in the human male. Philadelphia, PA: W.B. Saunders Company. 
Kirana, P., Papaharitou, S., Athanasiadis, L., Nakopoulou, E., Salpiggidis, G., Moysidis, K.,... Hatzichristou, D. (2009). A conceptual framework for the evolution of sexual medicine and a model for the development of alternative sexual health services: 10-year experience of the Center for Sexual and Reproductive Health. The Journal of Sexual Medicine, 6, 2405-2416. doi: 10.1111/j.1743-6109.2009.01320.x

Kline, R.B. (1998). Principles and practices of structural equation modeling. New York, NY: Guilford.

Lang, F.R., Rohr, M.K., \& Williger, B. (2011). Modeling success in life-span psychology: The principles of selection, optimization, and compensation. In K. Fingerman, C. Berg, J. Smith, \& T. Antonucci (Eds.), Handbook of Life-Span Development (pp. 57-85). New York, NY: Springer Publishing Company.

Laumann, E.O., Paik, A., Glasser, D.B., Kang, J.H., Wang, T., Levinson, B.,...Gingell, C. (2006). A cross-national study of subjective sexual well-being in older men and women: Findings from the Global Study of Sexual Attitudes and Behaviors. Archives of Sexual Behavior, 35, 145-161. doi: 10.1007/s10508-005-9005-3

Lawton, M. P., Kleban, M. H., Dean, J., Rajagopal, D., \& Parmelee, P. A. (1992). The factorial generality of brief positive and negative affect measures. Journal of Gerontology: Psychological Sciences, 47, 228-237.

Lee, Y., Jussim, L.J., \& McCauley, C.R. (Eds.). (1996). Stereotype accuracy: Toward appreciating group differences. Washington, DC: American Psychological Association.

Lichtenstein, B. (2008). 'Exemplary elders': Stigma, stereotypes, and sexually transmitted infections among older African Americans. Current Sociology, 56, 99-114. doi: 10.1177/0011392107084381 
Lindau, S.T., \& Gavrilova, N. (2010). Sex, health, and years of sexually active life gained due to good health: evidence from two US population based cross sectional surveys of ageing. $B M J$. Advance online publication. doi: 10.11136/bmj.c810

Lindau, S.T., Schumm, L.P., Laumann, E.O., Levinson, W., O’Muircheartaigh, C.A., \& Waite, L.J. (2007). A study of sexuality and health among older adults in the United States. The New England Journal of Medicine, 357, 762-774.

Logan, J.R., Ward, R., \& Spitze, G. (1992). As old as you feel: Age identity in middle and later life. Social Forces, 71(2), 451-467.

Lopez, M.H., \& Dockterman, D. (2011). U.S. Hispanic country-of-origin counts for nation, top 30 metropolitan areas. Retrieved from Pew Hispanic Center website: http://www.pewhispanic.org/files/2011/05/142.pdf

Mason, W., \& Suri, S. (2012). Conducting behavioral research on Amazon's Mechanical Turk. Behavior Research Methods, 44, 1-23. doi: 10.3758/s13428-011-0124-6

Matsumoto, D., Kouznetsova, N., Ray, R., Ratzlaff, C., Biehl, M., \& Raroque, J. (1999). Psychological culture, physical health, and subjective well-being. Journal of Gender, Culture, and Health, 4, 1-18.

Matthias, R.E., Lubben, J.E., Atchison, K.A., \& Schweitzer, S.O. (1997). Sexual activity and satisfaction among very old adults: Results from a community-dwelling Medicare population survey. The Gerontologist, 37, 6-14.

Moore, K.L. (2010). Sexuality and sense of self in later life: Japanese men's and women's reflections on sex and aging. Journal of Cross Cultural Gerontology, 25, 149-163. doi: $10.1007 / \mathrm{s} 10823-010-9115-9$ 
Mosher, C.E., \& Danoff-Burg, S. (2005). Agentic and communal personality traits: Relations to attitudes toward sex and sexual experiences. Sex Roles, 52, 121-129. doi: $10.1007 / \mathrm{s} 11199-005-1199-2$

Neugarten, B. L. (1974). Age groups in American society and the rise of the young-old. Annals of the American Academy of Political and Social Science, 415, 187-198.

Olson, J.M., \& Zanna, M.P. (1993). Attitudes and attitude change. Annual Review of Psychology, 44, 117-154.

Parker, R. (2009). Sexuality, culture, and society: Shifting paradigms in sexuality research. Culture, Health \& Sexuality, 11(3), 251-266. doi: 10.1080/13691050701606941

Part, K., Rahu, K., Rahu, M., \& Karro, H. (2008). Factors associated with Estonian adolescents' sexuality-related knowledge: Findings from the 1994 and 1999 KISS studies. The European Journal of Contraception and Reproductive Health Care, 13(2), 173-181.

Patrick, J.H., Cottrell, L.E., \& Barnes, K.A. (2001). Gender, emotional support, and well being among the rural elderly. Sex Roles, 45, 15-29.

Rheaume, C., \& Mitty, E. (2008). Sexuality and intimacy in older adults. Geriatric Nursing, 29, 342-349. doi: 10.1016/j.gerinurse.2008.08.004

Ross, C.E., \& Mirowsky, J. (1999). Refining the association between education and health: The effects of quantity, credential, and selectivity. Demography, 36(4), 445-460.

Rowe, J.W., \& Kahn, R.L. (1997). Successful aging. The Gerontologist, 37(4), 433-440.

Schiavi, R.C. (2010). Aging and male sexuality [Cambridge Books Online Version]. doi: 10.1017/CB09780511585098.002

Schmidt, F.L., Le, H., \& Ilies, R. (2003). Beyond alpha: An empirical examination of the effects of different sources of measurement error on reliability estimates for measures of 
individual differences constructs. Psychological Methods, 8(2), 206-224. doi: 10.1037/1082-989X.8.2.206

Shea, J.L. (2011). Older women, marital relationships, and sexuality in China. Ageing International, 36, 361-377. doi: 10.1007/s12126-011-9114-3

Skultety, K.M. (2007). Addressing issues of sexuality with older couples. Generations, 31, 3137.

Steinke, E.E. (1994). Knowledge and attitudes of older adults about sexuality in ageing: A comparison of two studies. Journal of Advanced Nursing, 19, 447-485.

Tabachnick, B.G., \& Fidell, L.S. (2013). Using multivariate statistics. Boston, MA: Pearson. Thompson, W.K., Charo, L., Vahia, I.V., Depp, C., Allison, M., Jeste, D.V. (2011). Association between higher levels of sexual function, activity, and satisfaction and self-rated successful aging in older postmenopausal women. Journal of American Geriatrics Society, 59, 1503-1508. doi: 10.1111/j.1532-5415.2011.03495.x

Thurstone, L.L. (1947). Multiple-factor analysis. Chicago, IL: The University of Chicago Press.

Tobin, C.T. (2011). Development of the Sexual Attitudes and Experiences Scale (SAES). The College Student Journal, 45, 352-368.

Tolman, D.L., \& McClelland, S.I. (2011). Normative sexuality development in adolescence: A decade in review 2000-2009. Journal of Research on Adolescence, 21(1), 242-255. doi: 10.1111/j.1532-7795.2010.00726.x

Tolman, D.L., Striepe, M.I., \& Harmon, T. (2003). Gender matters: Constructing a model of adolescent sexual health. The Journal of Sex Research, 40(1), 4-12.

United States Census Bureau, Education and Social Stratification Branch (2012). 2012 Annual social and economic supplement: Table 3. Detailed years of school completed by people 
25 years and over by sex, age groups, race, and Hispanic origin: 2012. Retrieved from http://www.census.gov/hhes/socdemo/education/data/cps/2012/tables.html

United States Department of Health and Human Services, National Institute of Mental Health (2010). Older adults: Depression and suicide facts (fact sheet). Retrieved from: www.nimh.gov/health/publications/older-adults-depression-and-suicide-facts-fact sheet/index.shtml

Waite, L.J., Laumann, E.O., Das, A., \& Schumm, L.P. (2009). Sexuality measures of partnerships, practices, attitudes, and problems in the national social life, health, and aging study. Journal of Gerontology: Social Sciences, 64B(S1), i56-i66. doi: 10.1093/geronb/gbp038.

Wang, T.F., Lu, C.H., Chen, I.J., \& Yu, S. (2008). Sexual knowledge, attitudes, and activity of older people in Taipei, Taiwan. Journal of Clinical Nursing, 17, 443-450. doi: 10.1111/j.1365-2702.2007.02003.x

Ware, J.E., Kosinski, M., \& Keller, S.D. (1996). A 12-item short-form health survey: Construction of scales and preliminary tests of reliability and validity. Medical Care, 34 (3), 220-233.

Weeks, D.J. (2002). Sex for the mature adult: health, self-esteem, and countering ageist stereotypes. Sexual and Relationship Therapy, 17, 231-240.

doi: $10.1080 / 14681990220149031$

White, C.B. (1982). A scale for the assessment of attitudes and knowledge regarding sexuality in the aged. Archives of Sexual Behavior, 11, 491-502. 
Wilson, E.K., Dalberth, B.T., Koo, H.P., \& Gard, J.C. (2010). Parents' perspectives on talking to preteenage children about sex. Perspectives on Sexual \& Reproductive Health, 42(1), 5663. doi: $10.1363 / 4205610$

Woloski-Wruble, A.C., Oliel, Y., Leefsma, M., \& Hochner-Celnikier, D. (2010). Sexual activities, sexual and life satisfaction, and successful aging in women. The Journal of Sexual Medicine, 7, 2401-2410. doi: 10.1111/j.1743-6109.2010.01747.x

Zeiss, A.M., \& Kasl-Godley, J. (2001). Sexuality in older adults' relationships. Generations, $25,18-25$.

Zickuhr, K., \& Madden, M. (2012). Older adults and internet use. Retrieved from Pew Research Center website: http://www.pewinternet.org/ /media//Files/Reports/2012/PIP_Older_ adults_and_internet_use.pdf 
Table 1. Sample means, standard deviations, percentages, and scale reliabilities.

\begin{tabular}{|c|c|c|}
\hline Variable & $M(S D)$ & $\alpha$ (No. items) \\
\hline \multicolumn{3}{|l|}{ Demographics } \\
\hline Age & $54.35(7.95)$ & \\
\hline$\%$ Male & $50.1 \%$ & \\
\hline$\%$ White & $52.6 \%$ & \\
\hline$\%$ Partnered/Married & $64.9 \%$ & \\
\hline \multicolumn{3}{|l|}{ Sex Variables } \\
\hline$\%$ Sexually Active & $71.7 \%$ & \\
\hline$\%$ Engaging in Sexual Activity at least Monthly & $45.8 \%$ & \\
\hline Overall Satisfaction & $3.40(1.08)$ & \\
\hline Physical Satisfaction & $3.52(.99)$ & \\
\hline Emotional Satisfaction & $3.68(1.06)$ & \\
\hline Frequency Satisfaction & $3.13(1.05)$ & \\
\hline Self-Reported Interest & $3.82(1.22)$ & \\
\hline NSHAP Interest & $6.03(1.96)$ & $0.67(2)$ \\
\hline ASKAS Knowledge ${ }^{\text {a }}$ & $43.96(14.85)$ & $0.92(35)$ \\
\hline Contraceptive/STI Knowledge & $6.48(1.80)$ & $0.65(4)$ \\
\hline ASKAS Attitudes & $74.16(21.89)$ & $0.91(26)$ \\
\hline NSHAP Mores & $14.43(3.47)$ & $0.76(5)$ \\
\hline \multicolumn{3}{|l|}{ Well-Being Variables } \\
\hline Subjective Happiness & $5.06(1.27)$ & \\
\hline PGC PA & $17.65(3.37)$ & $0.80(5)$ \\
\hline PGC NA & $12.72(4.02)$ & $0.86(5)$ \\
\hline SF-12 Physical Functioning Subscale & $75.21(28.38)$ & $0.71(2)$ \\
\hline SF-12 Role Physical Subscale & $63.42(43.36)$ & $0.77(2)$ \\
\hline SF-12 Bodily Pain Subscale & $76.63(24.25)$ & \\
\hline SF-12 General Health Subscale & $60.16(24.51)$ & \\
\hline SF-12 Vitality Subscale & $55.59(23.59)$ & \\
\hline SF-12 Social Functioning Subscale & $74.39(24.23)$ & \\
\hline SF-12 Role Emotional Subscale & 72.73(39.51) & $0.72(2)$ \\
\hline SF-12 Mental Health Subscale & $65.56(20.83)$ & $0.70(2)$ \\
\hline
\end{tabular}

Note. NSHAP = National Social Life, Health, and Aging Project; ASKAS = Aging Sexual Knowledge and Attitudes Scale; PGC = Philadelphia Geriatric Center; PA = Positive Affect; NA = Negative Affect; SF-12 = Short Form Health Survey.

${ }^{\mathrm{a}}$ The way the ASKAS Knowledge subscale was scored differs from the traditional scoring proposed by White (1982). Here, correct answers=2, incorrect answers=1, and "I don't know" responses $=0$. This was done for ease of interpretation with higher scores indicating more knowledge. 
Table 2. Bivariate correlations of key demographics and study variables.

\begin{tabular}{|c|c|c|c|c|c|c|c|c|c|c|c|c|c|c|}
\hline Measure & 1 & 2 & 3 & 4 & 5 & 6 & 7 & 8 & 9 & 10 & 11 & 12 & 13 & 14 \\
\hline 1. Age & -- & .02 & $-.15 *$ & $-.29 * *$ & -.04 & .02 & .04 & .01 & $-.23 * *$ & $-.23 * *$ & .01 & -.12 & .03 & .07 \\
\hline 2. Gender & & -- & -.07 & -.08 & -.05 & .03 & .00 & .03 & $-.27 * *$ & $-.29 * *$ & .02 & $.22 * *$ & -.12 & $.26^{* *}$ \\
\hline 3. Race & & & -- & .05 & .03 & -.07 & -.05 & .00 & .02 & .07 & -.02 & $-.16^{*}$ & $.20 * *$ & .00 \\
\hline 4. Freq. of Sexual Activity & & & & -- & $.45^{* *}$ & $.36 * *$ & $.35 * *$ & $.42 * *$ & $.46^{* *}$ & $.51 * *$ & $.19 * *$ & $.13^{*}$ & $-.22 * *$ & -.04 \\
\hline 5. Satisfaction-Overall & & & & & -- & $.63 * *$ & $.55^{* *}$ & $.57 * *$ & $.32 * *$ & $.23 * *$ & .03 & -.06 & -.14 & .04 \\
\hline 6. Satisfaction-Physical & & & & & & -- & $.67 * *$ & $.56 * *$ & $.35 * *$ & $.29 * *$ & .00 & .01 & $-.26 * *$ & .09 \\
\hline 7. Satisfaction-Emotional & & & & & & & -- & $.53 * *$ & $.26^{* *}$ & $.19 *$ & .06 & .03 & $-.24 * *$ & .12 \\
\hline 8. Satisfaction-Frequency & & & & & & & & -- & $.17 *$ & .08 & -.03 & -.10 & -.01 & .12 \\
\hline 9. Self-reported Interest & & & & & & & & & -- & $.68 * *$ & .12 & .07 & $-.28 * *$ & $-.22 * *$ \\
\hline 10.NSHAP Sexual Interest & & & & & & & & & & -- & $.18^{* *}$ & .08 & $-.31 * *$ & $-.31 * *$ \\
\hline 11. ASKAS Knowledge & & & & & & & & & & & -- & $.16^{*}$ & $-.24 * *$ & -.04 \\
\hline 12. Risk Knowledge & & & & & & & & & & & & -- & $-.41 * *$ & -.02 \\
\hline 13. ASKAS Attitudes & & & & & & & & & & & & & -- & $.28 * *$ \\
\hline 14. NSHAP Mores & & & & & & & & & & & & & & -- \\
\hline 15. PGC NA & -.05 & .05 & .05 & $-.16^{*}$ & $-.22 * *$ & $-.23 * *$ & $-.25 * *$ & $-.22 * *$ & $-.20 * *$ & -.05 & -.10 & -.01 & .06 & -.03 \\
\hline 16. PGC PA & -.06 & .07 & -.04 & $.21 * *$ & $.25^{* *}$ & $.29 * *$ & $.30 * *$ & $.22 * *$ & $.18^{*}$ & .08 & .12 & .10 & $-.17 *$ & .13 \\
\hline 18. SF-12 MH & .04 & -.03 & -.03 & $.21 * *$ & $.20 *$ & $.21 *$ & $.28 * *$ & $.22 * *$ & $.22 * *$ & .06 & .08 & .08 & -.11 & .11 \\
\hline 19. SF-12-Vitality & -.06 & -.05 & $.14 *$ & $.23 * *$ & $.35 * *$ & $.34 * *$ & $.28 * *$ & $.31 * *$ & $.27 * *$ & $.19 * *$ & -.01 & -.07 & .00 & .03 \\
\hline 20. SF-12 RE & .05 & .01 & -.08 & .12 & $.19 *$ & $.18 *$ & $.22 * *$ & $.21 *$ & .13 & .00 & -.04 & .02 & -.07 & .07 \\
\hline 21. SF-12 SF & -.05 & .01 & -.08 & $.22 * *$ & $.18^{*}$ & .14 & $.20 *$ & $.19 *$ & $.19 * *$ & .09 & .00 & .10 & $-.14 *$ & .06 \\
\hline 22. SF-12 GH & -.06 & -.01 & -.07 & $.22 * *$ & $.20 *$ & $.22 * *$ & $.16^{*}$ & $.20 *$ & $.21 * *$ & $.17 *$ & .07 & .05 & -.12 & -.02 \\
\hline 23. SF-12 PF & $-.15^{*}$ & .03 & -.05 & $.28 * *$ & .06 & .14 & $.16^{*}$ & .10 & $.24 * *$ & $.16^{*}$ & -.05 & .11 & $-.16^{*}$ & -.02 \\
\hline 24. SF-12 RP & -.13 & .02 & -.02 & $.14 *$ & .05 & .09 & .10 & .03 & $.25^{* *}$ & .13 & -.03 & .07 & -.07 & -.09 \\
\hline \multirow[t]{2}{*}{ 25. SF-12 BP } & -.12 & -.02 & -.03 & $.18^{*}$ & .09 & .13 & .16 & .15 & $.18^{*}$ & .13 & -.06 & .08 & -.09 & .01 \\
\hline & 15 & 16 & 17 & 18 & 19 & 20 & 21 & 22 & 23 & 24 & 25 & & & \\
\hline 15 & -- & $-.51 * *$ & $-.47 * *$ & $-.72 * *$ & $-.36 * *$ & $-.45^{* *}$ & $-.41 * *$ & $-.23 * *$ & $-.15^{* *}$ & $.18^{*}$ & $-.22 * *$ & & & \\
\hline 16 & & -- & $.65^{* *}$ & $.64 * *$ & $-.52 * *$ & $.31 * *$ & $.23 * *$ & $.34 * *$ & $.24 * *$ & $.17 *$ & .12 & & & \\
\hline 17 & & & -- & $.64 * *$ & $.52 * *$ & $.36 * *$ & $.26 * *$ & $.37 * *$ & $.30 * *$ & $.22 * *$ & $.24 * *$ & & & \\
\hline 18 & & & & -- & $.51 * *$ & $.56 * *$ & $.47 * *$ & $.33 * *$ & $.30 * *$ & $.28 * *$ & $.31 * *$ & & & \\
\hline 19 & & & & & -- & $.31 * *$ & $.34 * *$ & $.49 * *$ & $.40 * *$ & $.42 * *$ & $.38 * *$ & & & \\
\hline 20 & & & & & & -- & $.48 * *$ & $.17 *$ & $.28 * *$ & $.29 * *$ & $.30 * *$ & & & \\
\hline 21 & & & & & & & -- & $.39 * *$ & $.41 * *$ & $.44 * *$ & $.50 * *$ & & & \\
\hline 22 & & & & & & & & -- & $.46^{* *}$ & $.46^{* *}$ & $.42 * *$ & & & \\
\hline
\end{tabular}

(Table 2 continues) 
(Table 2 continued)

Note. The row and column numbers correspond to the first block. NSHAP = National Social Life, Health, and Aging Project; ASKAS = Aging Sexual Knowledge and Attitudes Scale; PGC = Philadelphia Geriatric Center; PA = Positive Affect; NA = Negative Affect; SF-12 = Short Form Health Survey; MH = Mental Health; RE = Role Emotional; SF = Social Functioning; GH = General Health; PF $=$ Physical Functioning; RP = Role Physical; BP = Bodily Pain.

${ }^{*} p<.01 .{ }^{* *} p<.001$ 
Table 3. Mean differences by gender on key sexuality variables.

\begin{tabular}{|c|c|c|c|c|c|c|c|}
\hline \multirow[b]{2}{*}{ Variable } & \multicolumn{2}{|c|}{ Men } & \multicolumn{2}{|c|}{ Women } & \multirow[b]{2}{*}{$t(d f)$} & \multirow[b]{2}{*}{$p$} & \multirow[b]{2}{*}{ Cohen's $d$} \\
\hline & $M$ & $S D$ & $M$ & $S D$ & & & \\
\hline Sexual Interest Scale & 10.73 & 2.63 & 8.97 & 2.95 & $6.06(365)$ & .00 & .63 \\
\hline NSHAP Mores Scale & 13.54 & 3.47 & 15.33 & 3.25 & $-5.08(365)$ & .00 & -.53 \\
\hline ASKAS Attitudes & 76.74 & 21.22 & 71.57 & 22.30 & $2.28(365)$ & .02 & .24 \\
\hline ASKAS Knowledge & 43.60 & 14.86 & 44.32 & 14.87 & $-.46(365)$ & .64 & -.05 \\
\hline Risk Knowledge & 6.09 & 2.03 & 6.86 & 1.44 & $-4.21(329.96)$ & .00 & -.44 \\
\hline Sexual Frequency & 1.24 & .84 & 1.11 & .84 & $1.48(365)$ & .14 & .15 \\
\hline $\begin{array}{l}\text { Sexual Satisfaction- } \\
\text { Overall }\end{array}$ & 2.55 & 1.79 & 2.32 & 1.78 & $1.27(365)$ & .20 & .13 \\
\hline $\begin{array}{l}\text { Sexual Satisfaction- } \\
\text { Composite }\end{array}$ & 7.59 & 5.03 & 7.21 & 5.31 & $.69(365)$ & .49 & .07 \\
\hline
\end{tabular}

Note. NSHAP = National Social Life, Health, and Aging Project; ASKAS = Aging Sexual

Knowledge and Attitudes Scale. 
Table 4. Mean differences by race on key sexuality variables.

\begin{tabular}{|c|c|c|c|c|c|c|c|c|c|}
\hline \multirow[b]{2}{*}{ Variable } & \multicolumn{2}{|c|}{ Whites } & \multicolumn{2}{|c|}{ African Americans } & \multicolumn{2}{|c|}{ Hispanic Americans } & \multirow[b]{2}{*}{$F(d f, d f)$} & \multirow[b]{2}{*}{$p$} & \multirow[b]{2}{*}{$\eta_{p}^{2}$} \\
\hline & $M$ & $S D$ & $M$ & $S D$ & $M$ & $S D$ & & & \\
\hline $\begin{array}{l}\text { Sexual Interest } \\
\text { Scale }\end{array}$ & 9.60 & 2.95 & 10.39 & 2.87 & 9.79 & 2.89 & $2.45(2,364)$ & .09 & .01 \\
\hline $\begin{array}{l}\text { NSHAP Mores } \\
\text { Scale }\end{array}$ & 14.48 & 3.38 & 14.24 & 3.70 & 14.59 & 3.44 & $.25(2,364)$ & .78 & .001 \\
\hline $\begin{array}{l}\text { ASKAS } \\
\text { Attitudes }\end{array}$ & 70.85 & 20.90 & 74.14 & 22.09 & 82.97 & 22.03 & $8.45(2,364)$ & .00 & .04 \\
\hline $\begin{array}{l}\text { ASKAS } \\
\text { Knowledge }\end{array}$ & 44.18 & 14.32 & 44.04 & 16.52 & 43.26 & 13.94 & $.10(2,364)$ & .90 & .001 \\
\hline $\begin{array}{l}\text { Risk } \\
\text { Knowledge }\end{array}$ & 6.69 & 1.72 & 6.48 & 1.74 & 5.90 & 1.98 & $5.24(2,364)$ & .006 & .03 \\
\hline $\begin{array}{l}\text { Sexual } \\
\text { Frequency }\end{array}$ & 1.10 & .86 & 1.32 & .82 & 1.16 & .82 & $2.13(2,364)$ & .12 & .01 \\
\hline $\begin{array}{l}\text { Sexual } \\
\text { Satisfaction- } \\
\text { Overall }\end{array}$ & 2.31 & 1.82 & 2.54 & 1.66 & 2.62 & 1.87 & $1.03(2,364)$ & .36 & .01 \\
\hline $\begin{array}{l}\text { Sexual } \\
\text { Satisfaction- } \\
\text { Composite }\end{array}$ & 7.13 & 5.33 & 7.76 & 4.86 & 7.62 & 5.18 & $.58(2,364)$ & .56 & \\
\hline
\end{tabular}

Note. NSHAP $=$ National Social Life, Health, and Aging Project; ASKAS = Aging Sexual Knowledge and Attitudes Scale. 
Table 5. Structural equation results for hypothesized full model.

\begin{tabular}{lccc}
\hline \multicolumn{1}{c}{ Variable } & $b(S E)$ & $\beta$ & CR \\
\hline Sexual Well-Being $(W B)$ & & Measurement Model & \\
Frequency in Past Year $\rightarrow$ WB & 1.000 & .91 & 33.15 \\
Overall Satisfaction $\rightarrow$ WB & $2.22(.07)$ & .95 & 35.21 \\
Component Satisfaction $\rightarrow$ WB & $6.55(.19)$ & .97 & \\
& & Structural Model & \\
Influence of Gender & & & -6.26 \\
Gender $\rightarrow$ Sexual Interest & $-1.79(.29)$ & -.31 & 5.09 \\
Gender $\rightarrow$ General Sexual Attitudes & $1.78(.35)$ & .26 & -2.24 \\
Gender $\rightarrow$ Age-Specific Sexual Attitudes & $-4.94(2.21)$ & -.11 & 10.83 \\
& & & 3.66 \\
Sexual Interest $\rightarrow$ WB & $.14(.01)$ & .53 & -2.25 \\
General Sexual Attitudes $\rightarrow$ WB & $.04(.01)$ & .17 & 2.08 \\
Age-Specific Sexual Attitudes $\rightarrow$ WB & $-.004(.002)$ & -.11 & .10 \\
Age-Specific Sexual Knowledge $\rightarrow$ WB & $.005(.002)$ & & \\
\hline
\end{tabular}

Note. $\mathrm{CR}=$ Critical Ratio. For critical ratios $>1.96, p<.05$. 
Table 6. Structural equation results for full model for men.

\begin{tabular}{lccc}
\hline \multicolumn{1}{c}{ Variable } & $b(S E)$ & $\beta$ & CR \\
\hline & & Measurement Model & \\
Sexual Well-Being $(W B)$ & 1.000 & .90 & 21.43 \\
Frequency in Past Year $\rightarrow$ WB & $2.22(.10)$ & .94 & 23.41 \\
Overall Satisfaction $\rightarrow$ WB & $6.47(.28)$ & .97 & 6.16 \\
Component Satisfaction $\rightarrow$ WB & & Structural Model & 2.82 \\
& $.13(.02)$ & .46 & -1.40 \\
Sexual Interest $\rightarrow$ WB & $.04(.02)$ & .19 & .96 \\
General Sexual Attitudes $\rightarrow$ WB & $-.004(.003)$ & .06 & \\
Age-Specific Sexual Attitudes $\rightarrow$ WB & $.003(.003)$ & & \\
Age-Specific Sexual Knowledge $\rightarrow$ WB & & & \\
\hline
\end{tabular}

Note. $\mathrm{CR}=$ Critical Ratio. For critical ratios $>1.96, p<.05$. 
Table 7. Structural equation results for full model for women.

\begin{tabular}{lccc}
\hline \multicolumn{1}{c}{ Variable } & $b(S E)$ & $\beta$ & CR \\
\hline Sexual Well-Being $(W B)$ & & Measurement Model & \\
Frequency in Past Year $\rightarrow$ WB & 1.000 & .92 & 25.65 \\
Overall Satisfaction $\rightarrow$ WB & $2.22(.09)$ & .97 & 26.27 \\
Component Satisfaction $\rightarrow$ WB & $6.68(.25)$ & .97 & \\
& & Structural Model & 9.05 \\
Sexual Interest to WB & $.16(.02)$ & .60 & 1.68 \\
General Sexual Attitudes $\rightarrow$ WB & $.03(.02)$ & .11 & -1.04 \\
Age-Specific Sexual Attitudes $\rightarrow$ WB & $-.003(.002)$ & -.07 & 2.07 \\
Age-Specific Sexual Knowledge $\rightarrow$ WB & $.007(.003)$ & .13 & \\
\hline
\end{tabular}

Note. $\mathrm{CR}=$ Critical Ratio. For critical ratios $>1.96, p<.05$. 
Table 8. Pattern and structure matrix for EFA with oblimin rotation of three factor solution of successful aging model.

\begin{tabular}{lcccc}
\hline \multicolumn{3}{c}{ Scale/Item } & \multicolumn{3}{c}{ Pattern coefficients } & Communalities \\
\hline & Comp. 1 & Comp. 2 & Comp. 3 & \\
\cline { 2 - 4 } PGC PA & $\mathbf{. 9 0 4}$ & .010 & -.052 & .781 \\
Global & $\mathbf{. 8 5 9}$ & .067 & .071 & .770 \\
Happiness & & -.125 & .006 & .753 \\
SF-12 MH & $\mathbf{. 8 2 8}$ & & -.013 & .946 \\
Satisfaction- & .019 & $\mathbf{- . 9 6 2}$ & & \\
Composite & & & & .932 \\
Satisfaction- & .034 & $\mathbf{- . 9 5 9}$ & .011 & \\
Overall & & & & .900 \\
Sexual & -.038 & $\mathbf{- . 9 5 5}$ & .017 & .767 \\
Frequency & & .053 & $\mathbf{. 9 1 3}$ & .731 \\
SF-12 RP & -.083 & .095 & $\mathbf{. 8 3 9}$ & .582 \\
SF-12 PF & -.034 & -.095 \\
SF-12 GH & .207 & .008 & $\mathbf{. 6 6 5}$ & \\
\hline
\end{tabular}

Note. Strongest loadings for each component are in boldface. $\mathrm{PGC}=$ Philadelphia Geriatric Center; PA = Positive Affect; SF-12 = Short Form Health Survey; MH = Mental Health; RP = Role Physical; PF = Physical Functioning; GH = General Health. 
Figure 1. Conceptual Model of Sexual Well-Being

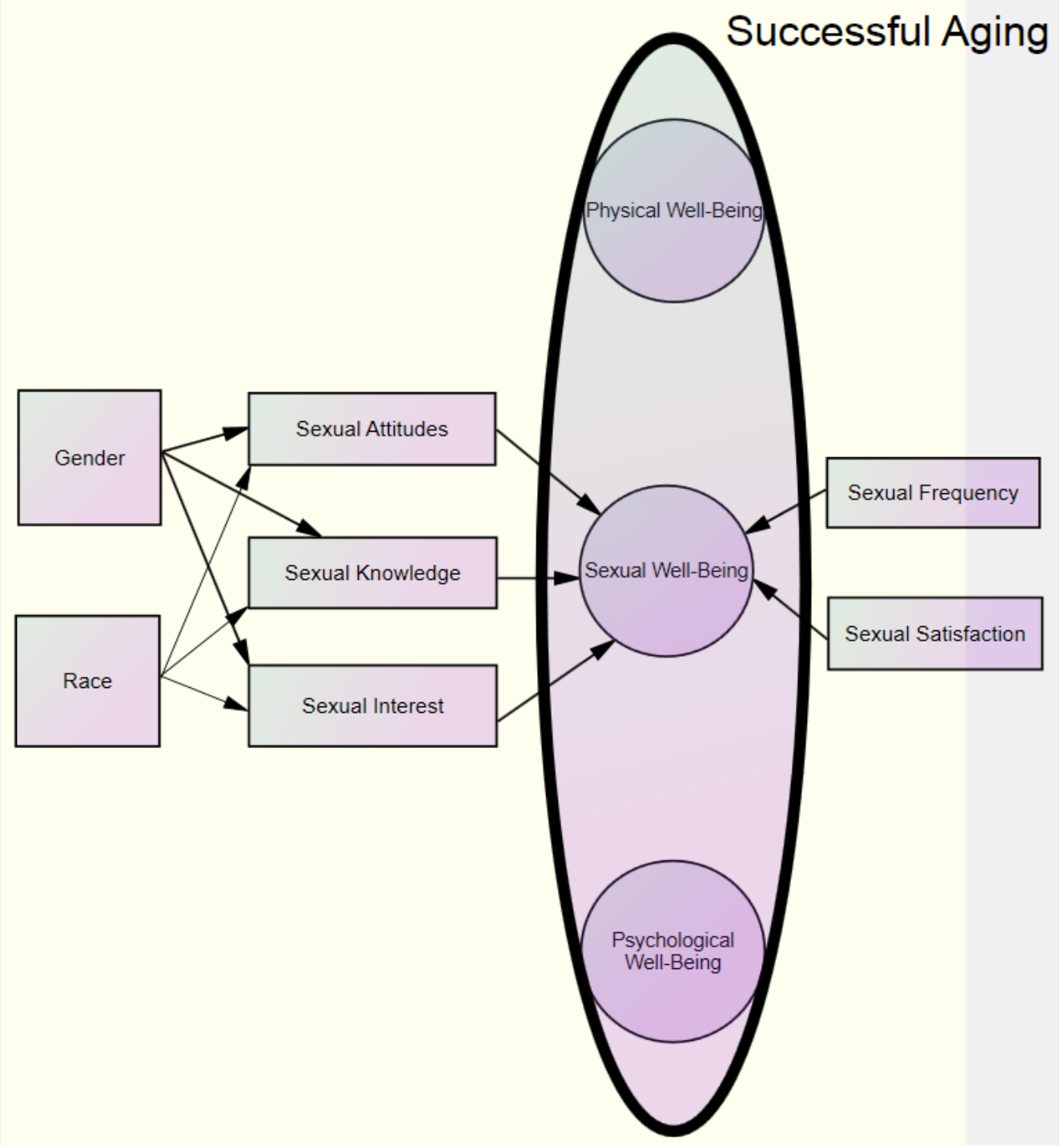

Figure 1. Conceptual model of sexual well-being as hypothesized. The demographic characteristics of gender and race/ethnicity are believed to influence sexual attitudes, interest, and knowledge. These variables will in turn impact sexual well-being measured by one objective measure, frequency of sexual activity, and two subjective, sexual satisfaction measures. Finally, sexual well-being is believed to relate to, but exist independently from physical and psychological well-being. Physical and psychological well-being form the basis of many successful aging models, and it is hypothesized that sexual well-being represents another pillar. 
Figure 2. Sexual Well-Being Structural Model with Standardized Path Coefficients

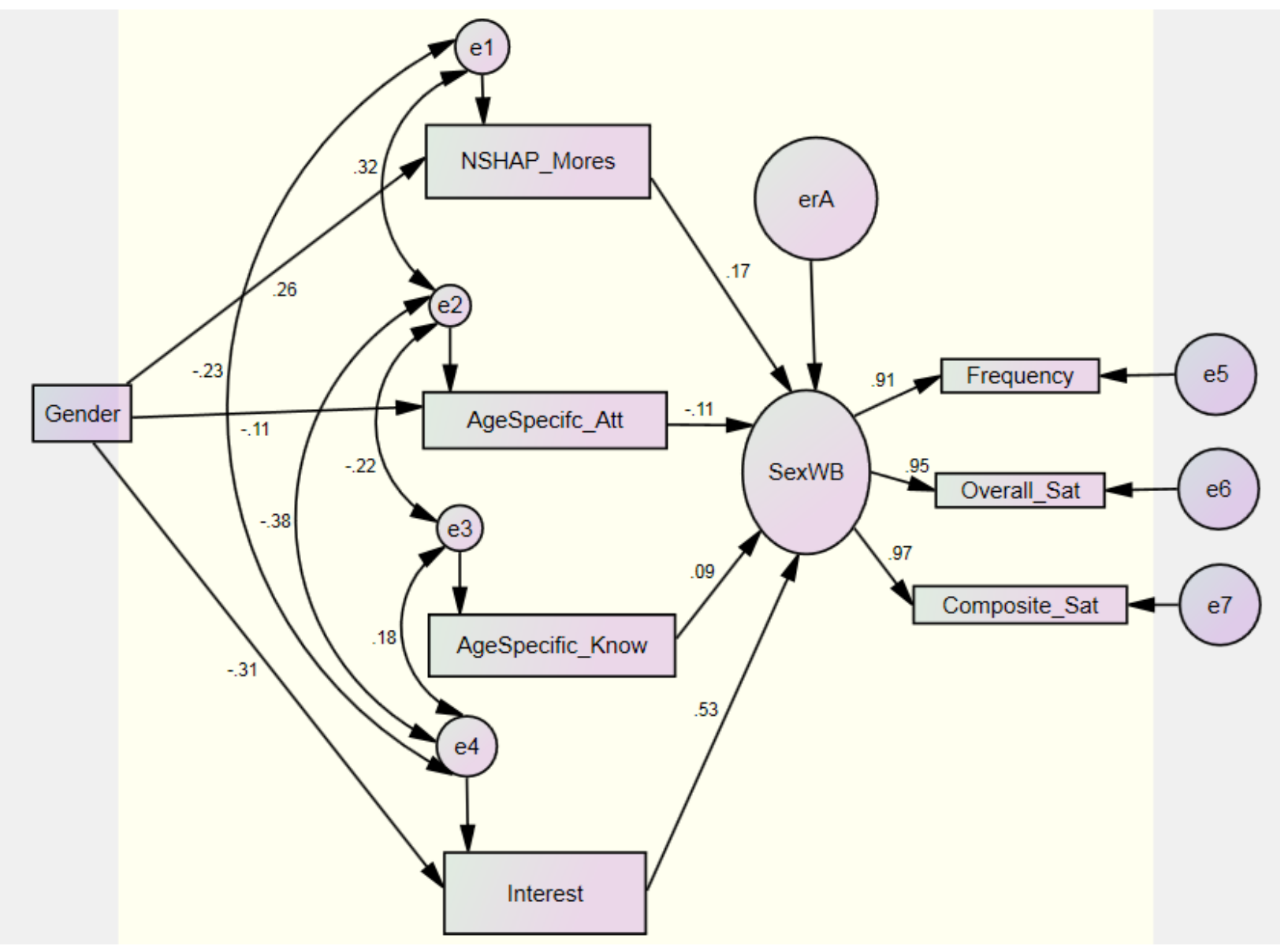

Figure 2. Sexual well-being is a latent construct in the model, conceptualized with respect to sexual frequency, overall sexual satisfaction, and a composite measure of sexual satisfaction. The four indicators (general sexual attitudes, age-specific sexual attitudes, age-specific sexual knowledge, and sexual interest) all significantly relate to sexual well-being. Gender differences are supported for general sexual attitudes (men more open), age-specific sexual attitudes (women more open), and sexual interest (men report higher levels). 


\section{Appendix A}

\section{Philadelphia Geriatric Center Positive Affect \& Negative Affect Scale}

"During the past week, how often have you felt..."

"Happy” (Never, Rarely, Sometimes, Frequently, Very Frequently)

“Annoyed” (Never, Rarely, Sometimes, Frequently, Very Frequently)

"Warm-hearted" (Never, Rarely, Sometimes, Frequently, Very Frequently)

“Irritated” (Never, Rarely, Sometimes, Frequently, Very Frequently)

“Content” (Never, Rarely, Sometimes, Frequently, Very Frequently)

“Sad” (Never, Rarely, Sometimes, Frequently, Very Frequently)

"Energetic" (Never, Rarely, Sometimes, Frequently, Very Frequently)

"Worried" (Never, Rarely, Sometimes, Frequently, Very Frequently)

"Interested” (Never, Rarely, Sometimes, Frequently, Very Frequently)

“Depressed” (Never, Rarely, Sometimes, Frequently, Very Frequently)

\section{Philadelphia Geriatric Center Multilevel Assessment Instrument-Selected Items}

"Do your health problems stand in the way of your doing the things you want to do?"

(Not at All, A little, Quite a Bit)

"Is your health now better, about the same, or not as good as it was 3 years ago?" (Not as

Good, About the Same, Better)

"Compared with most other people your age, would you say your health is:" (Not as

Good, About the Same, Better)

\section{Short Form Health Survey (36 item) (Physical Functioning Scale)}

"Does your health now limit you in..." 
"Vigorous activities, such as running, lifting heavy objects, or participating in strenuous sports" (No, Not at all Limited, Yes, Limited a Little, Yes, Limited a Lot) "Lifting or carrying groceries" (No, Not at all Limited, Yes, Limited a Little, Yes, Limited a Lot)

"Climbing one flight of stairs" (No, Not at all Limited, Yes, Limited a Little, Yes, Limited a Lot)

"Bending, kneeling or stooping" (No, Not at all Limited, Yes, Limited a Little, Yes, Limited a Lot)

"Walking more than one mile" (No, Not at all Limited, Yes, Limited a Little, Yes, Limited a Lot)

"Walking several blocks" (No, Not at all Limited, Yes, Limited a Little, Yes, Limited a Lot)

"Walking one block" (No, Not at all Limited, Yes, Limited a Little, Yes, Limited a Lot)

“Bathing or dressing yourself” (No, Not at all Limited, Yes, Limited a Little, Yes, Limited a Lot)

\section{Short Form Health Survey (36-item)-Selected Items}

“Compared to one year ago, how would you rate your health in general now?" (Not as Good, About the Same, Better)

"During the past 4 weeks..."

"Have you cut down on the amount of time you spent on work or other activities as a result of your physical health?" (No, Yes) 
"Did you have difficulty performing work or other activities (for example, it took extra effort) as a result of your physical health?" (No, Yes)

"Did you cut down on the amount of time you spent on work or other activities as a result of any emotional problems (such as feeling depressed or anxious)?" (No, Yes)

“How much physical pain have you had?" (None, Some, A lot)

\section{Short Form Health Survey (12-item)}

General Health Subdomain. "In general, would you say your health is:" (Poor, Fair, Good, Very Good, Excellent)

Physical Functioning Subdomain. "Does your health now limit you in..."

"Moderate activities, such as moving a table, pushing a vacuum cleaner, bowling or playing golf" (No, Not at all Limited, Yes, Limited a Little, Yes, Limited a Lot)

"Climbing several flights of stairs" (No, Not at all Limited, Yes, Limited a Little, Yes, Limited a Lot)

Role Functioning (Physical) Subdomain. "During the past 4 weeks..."

"Have you accomplished less than you would like as a result of your physical health?" (No, Yes)

"Were you limited in the types of work or other activities as a result of your physical health?" (No, Yes)

Role Functioning (Emotional) Subdomain. "During the past 4 weeks..."

"Have you accomplished less than you like as a result of your emotional problems (such as feeling depressed or anxious)?" (No, Yes)

"Did you not do work or other activities as carefully as usual as a result of any emotional problems (such as feeling depressed or anxious)?" (No, Yes) 
Social Functioning Subdomain. "To what extent has your physical health or emotional problems interfered with your normal social activities with family, friends, neighbors or groups?” (Never, Sometimes, Often, Routinely)

Bodily Pain Subdomain. "How much did physical pain interfere with your normal work (including both work outside the home and housework)?" (Not at all, A little bit, Moderately, Quite a bit, Extremely)

Vitality Subdomain. "How much of the time in the past 4 weeks..."

"Did you have a lot of energy?" (None of the time, A little of the time, Some of the time, A good bit of the time, Most of the time, All of the time)

Mental Health Subdomain. "How much of the time in the past 4 weeks..."

"Have you felt downhearted and blue?" (None of the time, A little of the time, Some of the time, A good bit of the time, Most of the time, All of the time)

"Have you felt calm and peaceful?" (None of the time, A little of the time, Some of the time, A good bit of the time, Most of the time, All of the time)

\section{Sexual Experience-Open Ended}

"The following questions pertain to your sexual knowledge and experiences, both past and present. First, using single words or short phrases, describe your sexual history."

\section{Sexual Experience Scale}

"Please indicate if you have experienced each of the following at different points throughout your life. Check all that apply."

"Formal sex education (school, seminars, medical professionals)" (Never, As a Youth (0-19), As a Young Adult (20-40), As a Middle Adult (41-64), As an Older Adult $(65+))$ 
"Informal sex education (books, non-pornographic magazines, television, Internet" (Never, As a Youth (0-19), As a Young Adult (20-40), As a Middle Adult (4164), As an Older Adult (65+))

"Discussions about sex with parents or relatives" (Never, As a Youth (0-19), As a Young Adult (20-40), As a Middle Adult (41-64), As an Older Adult (65+))

"Discussion about sex with friends" (Never, As a Youth (0-19), As a Young Adult (20-40), As a Middle Adult (41-64), As an Older Adult (65+))

"Sexual contact through self-stimulation" (Never, As a Youth (0-19), As a Young Adult (20-40), As a Middle Adult (41-64), As an Older Adult (65+))

"Sexual contact with a partner without intercourse" (Never, As a Youth (0-19), As a Young Adult (20-40), As a Middle Adult (41-64), As an Older Adult (65+))

"Sexual intercourse with a partner" (Never, As a Youth (0-19), As a Young Adult (20-40), As a Middle Adult (41-64), As an Older Adult (65+))

"More than one partner in a given span of time (i.e., 2 or more different partners within the same year" (Never, As a Youth (0-19), As a Young Adult (20-40), As a Middle Adult (41-64), As an Older Adult (65+))

"Use of contraceptives" (Never, As a Youth (0-19), As a Young Adult (20-40), As a Middle Adult (41-64), As an Older Adult (65+))

"Use of erotic materials (pornography)" (Never, As a Youth (0-19), As a Young Adult (20-40), As a Middle Adult (41-64), As an Older Adult (65+))

"Tested for sexually transmitted infections" (Never, As a Youth (0-19), As a Young Adult (20-40), As a Middle Adult (41-64), As an Older Adult (65+)) 
"Diagnosed with a sexually transmitted infection" (Never, As a Youth (0-19), As

a Young Adult (20-40), As a Middle Adult (41-64), As an Older Adult (65+))

\section{Kinsey Sexual Orientation Scale}

"From the options below, select the option that best describes your sexual orientation." (Exclusively Heterosexual, Predominately heterosexual (with incidental homosexual experiences), Bisexual, Predominately homosexual (with incidental heterosexual experiences), Exclusively homosexual)

\section{Self-Reported Sexual Interest}

"How strong would you say your interest in sex is?" (Absent, Very Weak, Somewhat Weak, Somewhat Strong, Very Strong, Extremely Strong)

\section{Sexual Activity}

"In the past year, have you engaged in sexual activity without a partner (selfstimulation)?" (No, Yes)

"In the past year, have you engaged in sexual activity with a partner?" (No, Yes)

\section{Length of Relationship}

"How long has your relationship with your most recent sexual partner lasted? (Feel free to indicate length of time in days, months, or years.)"

\section{Overall Satisfaction}

"In general, would you say your current sexual relationship is:" (Not sexually active, Poor, Fair, Good, Very Good, Excellent)

\section{Dissatisfaction}

"If you feel any dissatisfaction with your current sexual relationship, please indicate your reasoning. (Select all that apply).” 


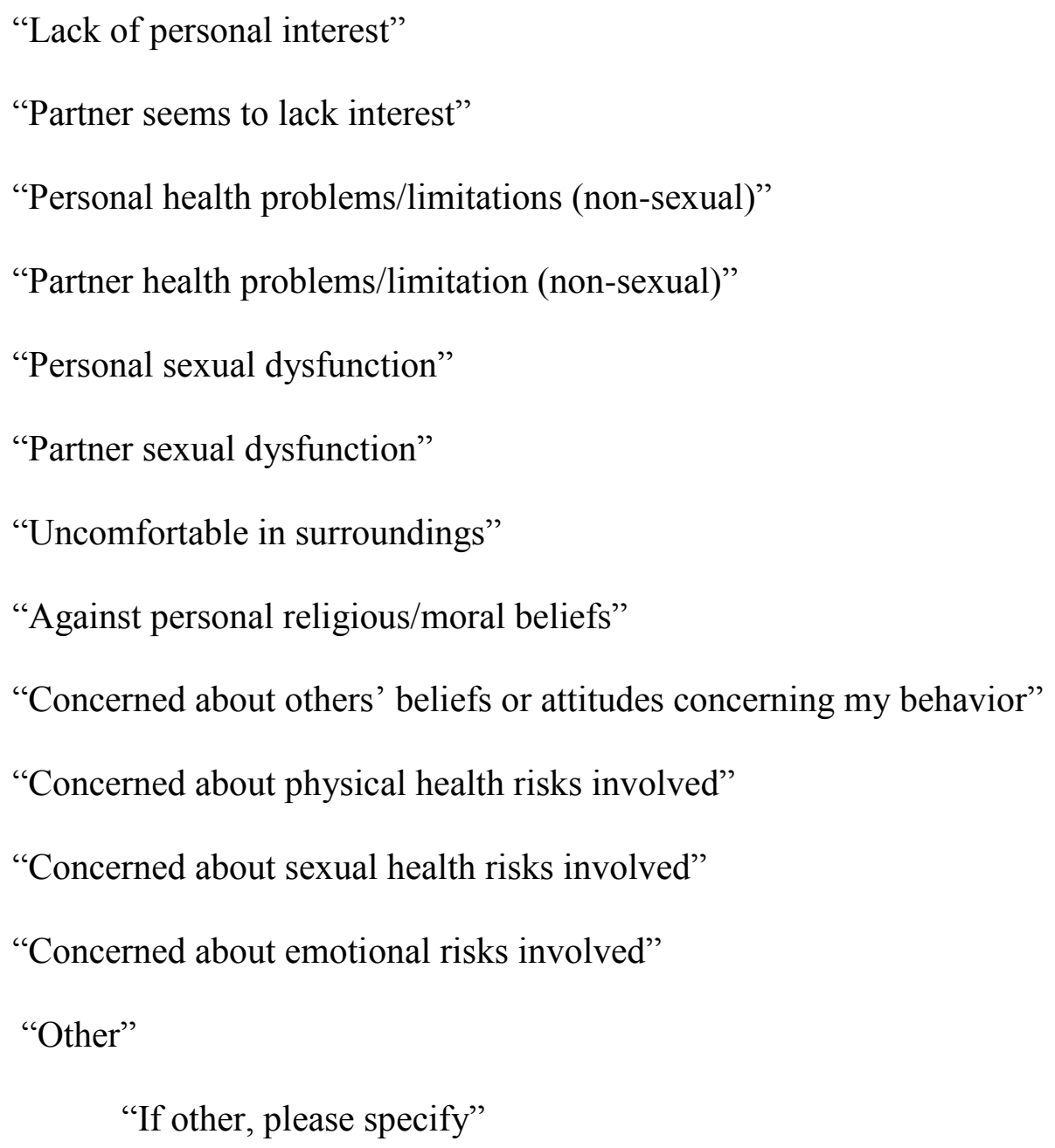

\section{Frequency}

"Select the choice below that best describes the frequency of your sexual activity with a partner during the past year.” (Daily, Weekly, Monthly, Quarterly, Twice a Year, Never)

\section{Specific Satisfaction}

"How satisfied are you with the frequency of your sexual activities with a partner during the past year?" (Not sexually active, Not at all, Slightly, Moderately, Very, Extremely)

"How physically satisfying do you find your sexual relationship with your partner to be?" (Not sexually active, Not at all, Slightly, Moderately, Very, Extremely) 
"How emotionally satisfying do you find your sexual relationship with your partner to be?" (Not sexually active, Not at all, Slightly, Moderately, Very, Extremely)

Not Sexually Active (Only those who responded as such)

"You have indicated that you have NOT been sexually active with a partner in the past year. From the following, select those explanations which fit your reasoning (you may select as many as you wish)."

"Lack of personal interest"

"Lack of partner interest"

"Personal health problems/limitations (non-sexual)"

"Partner health problems/limitations (non-sexual)"

"Personal sexual dysfunction"

"Partner sexual dysfunction"

"Lack of viable partner"

"Lack of opportunity (privacy, place, etc.)"

"Personal religious/moral beliefs"

"Others' beliefs or attitudes concerning my behavior"

"Concern about physical risks"

"Concern about sexually transmitted infections"

"Concern about emotional risks"

"Other"

"If other, please specify"

\section{Current Health Behaviors}

"How many hours in a typical week do you spend in paid work?" 
"How much sleep, on average, do you get? (hours per night)"

"What is your height?"

"What is your weight (pounds)?"

"What is your waist measurement? (inches)"

\section{Subjective Well-Being}

"I believe my life to be:” (Extremely unhappy, Very unhappy, Somewhat unhappy, Average, Somewhat happy, Very happy, Extremely happy)

\section{Over-the-counter Medication Usage}

"What types of over-the counter (OTC) medication do you take?"

"I do not use OTC medications."

"Joint supplements"

"Antacids"

"Allergy/sinus medications, including nasal sinus sprays"

"Pain relievers, including aspirin"

"Cold medicine, including cough syrup or throat lozenges"

"Anti-diarrhea medicine and laxatives"

"Nicotine gums or patches for smoking cessation"

"BenGay, Tiger Balm, or other external pain relievers"

"Sleep aids"

"Other"

“Other (please specify)"

\section{Body Image}


"I am satisfied with my overall appearance" (Strongly Disagree, Disagree, Neutral, Agree, Strongly Agree)

"I am satisfied with the appearance of my skin" (Strongly Disagree, Disagree, Neutral, Agree, Strongly Agree)

"I wish I were more muscular" (Strongly Disagree, Disagree, Neutral, Agree, Strongly Agree)

\section{NSHAP Attitude Items}

"Below is a list of statements. For each one, please choose if you think this is always wrong, almost always wrong, wrong only sometimes, or not wrong at all. All of these statements refer to adults."

"A married person having sexual relations with someone other than their marriage partner. Is this...” (Always Wrong, Almost Always Wrong, Wrong Only Sometimes, Not Wrong At All)

"What if the spouse is in advanced stages of dementia, such as Alzheimer's or other mental disease? Is this..." (Always Wrong, Almost Always Wrong, Wrong Only Sometimes, Not Wrong At All)

"What about if the spouse has a serious, long-term physical illness and cannot have sex. Is this..." (Always Wrong, Almost Always Wrong, Wrong Only Sometimes, Not Wrong At All)

"For the next set of statements, please choose whether you strongly agree, agree, disagree, or strongly disagree. These are just general statements; they are not about your specific relationship." 
"I would not have sex with someone unless I was in love with them." (Strongly Disagree, Disagree, Agree, Strongly Agree)

"My religious beliefs have shaped and guided my sexual behavior." (Strongly

Disagree, Disagree, Agree, Strongly Agree)

"Satisfactory sexual relations are essential to the maintenance of a relationship."

(Strongly Disagree, Disagree, Agree, Strongly Agree)

"The ability to have sex decreases as a person grows older." (Strongly Disagree, Disagree, Agree, Strongly Agree)

"For some people sex is a very important part of their lives and for others it is not very important at all. How important a part of your life would you say sex is?" (Not at all Important, Somewhat important, Moderately important, Very important, Extremely important)

"How often do you think about sex?" (Less than once a month, One to a few times a month, One to a few times a week, Every day, Several times a day)

\section{Aging Sexual Knowledge and Attitudes Scale-Attitude Subscale}

"Please answer the following."

"Aged people have little interest in sexuality (aged=65+ years of age)." (Strongly

Disagree, Disagree, Disagree a little, Neither Agree or Disagree, Agree a little, Agree, Strongly Agree)

"An aged person who shows sexual interest brings disgrace to himself/herself." (Strongly Disagree, Disagree, Disagree a little, Neither Agree or Disagree, Agree a little, Agree, Strongly Agree) 
"Institutions such as nursing homes ought not to encourage or support sexual activity of any sorts in its residents." (Strongly Disagree, Disagree, Disagree a little, Neither Agree or Disagree, Agree a little, Agree, Strongly Agree)

"Male and female residents of nursing homes ought to live on separate floors or in separate wings of the nursing home." (Strongly Disagree, Disagree, Disagree a little, Neither Agree or Disagree, Agree a little, Agree, Strongly Agree)

"Nursing homes have no obligation to provide adequate privacy for residents who desire to be alone, either by themselves or as a couple." (Strongly Disagree, Disagree, Disagree a little, Neither Agree or Disagree, Agree a little, Agree, Strongly Agree)

"As one becomes older (say past 65) interest in sexuality inevitably disappears." (Strongly Disagree, Disagree, Disagree a little, Neither Agree or Disagree, Agree a little, Agree, Strongly Agree)

"If a relative of mine living in a nursing home was to have a sexual relationship with another resident, I would complain to the management." (Strongly Disagree, Disagree, Disagree a little, Neither Agree or Disagree, Agree a little, Agree, Strongly Agree)

"If a relative of mine living in a nursing home was to have a sexual relationship with another resident, I would move my relative from this institution.” (Strongly Disagree, Disagree, Disagree a little, Neither Agree or Disagree, Agree a little, Agree, Strongly Agree)

"If a relative of mine living in a nursing home was to have a sexual relationship with another resident, I would stay out of it as it is not my concern." (Strongly Disagree, 
Disagree, Disagree a little, Neither Agree or Disagree, Agree a little, Agree, Strongly Agree)

"If I knew that a particular nursing home permitted and supported sexual activity in residents who desired such, I would not place a relative in that nursing home." (Strongly Disagree, Disagree, Disagree a little, Neither Agree or Disagree, Agree a little, Agree, Strongly Agree)

"It is immoral for older persons to engage in recreational sex." (Strongly Disagree, Disagree, Disagree a little, Neither Agree or Disagree, Agree a little, Agree, Strongly Agree)

"I would like to know more about the changes in sexual functioning in older years." (Strongly Disagree, Disagree, Disagree a little, Neither Agree or Disagree, Agree a little, Agree, Strongly Agree)

"I feel I know all I need to know about sexuality in the aged." (Strongly Disagree, Disagree, Disagree a little, Neither Agree or Disagree, Agree a little, Agree, Strongly Agree)

"I would complain to the management if I knew of sexual activity between any residents of a nursing home.” (Strongly Disagree, Disagree, Disagree a little, Neither Agree or Disagree, Agree a little, Agree, Strongly Agree)

"I would support sex education courses for aged residents of nursing homes." (Strongly Disagree, Disagree, Disagree a little, Neither Agree or Disagree, Agree a little, Agree, Strongly Agree) 
"I would support sex education courses for the staff of nursing homes." (Strongly Disagree, Disagree, Disagree a little, Neither Agree or Disagree, Agree a little, Agree, Strongly Agree)

"Masturbation is an acceptable sexual activity for older males." (Strongly Disagree, Disagree, Disagree a little, Neither Agree or Disagree, Agree a little, Agree, Strongly Agree)

"Masturbation is an acceptable sexual activity for older females." (Strongly Disagree, Disagree, Disagree a little, Neither Agree or Disagree, Agree a little, Agree, Strongly Agree)

"Institutions such as nursing homes ought to provide large enough beds for couples who desire to sleep together." (Strongly Disagree, Disagree, Disagree a little, Neither Agree or Disagree, Agree a little, Agree, Strongly Agree)

"Staff of nursing homes ought to be trained or educated with regard to sexuality in the aged and/or disabled." (Strongly Disagree, Disagree, Disagree a little, Neither Agree or Disagree, Agree a little, Agree, Strongly Agree)

"Residents of nursing homes ought not to engage in sexual activity of any sort." (Strongly Disagree, Disagree, Disagree a little, Neither Agree or Disagree, Agree a little, Agree, Strongly Agree)

"Institutions such as nursing homes should provide opportunities for the social interaction of men and women." (Strongly Disagree, Disagree, Disagree a little, Neither Agree or Disagree, Agree a little, Agree, Strongly Agree)

"Masturbation is harmful and ought to be avoided." (Strongly Disagree, Disagree, Disagree a little, Neither Agree or Disagree, Agree a little, Agree, Strongly Agree) 
"Institutions such as nursing homes should provide privacy so as to allow residents to engage in sexual behavior without fear of intrusion or observation." (Strongly Disagree, Disagree, Disagree a little, Neither Agree or Disagree, Agree a little, Agree, Strongly Agree)

"If family members object to a widowed relative engaging in sexual relations with another resident of a nursing home, it is the obligation of management and staff to make certain that such sexual activity is prevented." (Strongly Disagree, Disagree, Disagree a little, Neither Agree or Disagree, Agree a little, Agree, Strongly Agree)

"Sexual relations outside the context of marriage are always wrong." (Strongly Disagree, Disagree, Disagree a little, Neither Agree or Disagree, Agree a little, Agree, Strongly Agree)

\section{Aging Sexuality Knowledge and Attitudes Scale-Knowledge Subscale}

"The following items concern sexual and reproductive health."

"Sexual activity in aged persons is often dangerous to their health." (True, False, I don't know)

"Males over the age of 65 typically take longer to attain an erection of their penis than do young males." (True, False, I don't know)

"Males over the age of 65 usually experience a reduction in intensity of orgasm relative to younger males." (True, False, I don’t know)

"The firmness of erection in aged males is often less than that of younger persons." (True, False, I don’t know)

"The older female (65+ years of age) has reduced vaginal lubrication secretion relative to younger females." (True, False, I don't know) 
"The aged female takes longer to achieve adequate vaginal lubrication relative to younger females." (True, False, I don't know)

"The older female may experience painful intercourse due to reduced elasticity of the vagina and reduced vaginal lubrication." (True, False, I don't know)

“Sexuality is typically a life-long need." (True, False, I don't know)

"Sexual behavior in older people $(65+)$ increases the risk of heart attack." (True, False, I don't know)

"Most males over the age of 65 are unable to engage in sexual intercourse." (True, False, I don't know)

"The relatively most sexual younger people tend to become the relatively most sexual older people." (True, False, I don't know)

"There is evidence that sexual activity in older persons has beneficial physical effects on the participants." (True, False, I don't know)

"Sexual activity may be psychologically beneficial to older people." (True, False, I don't know)

“Most older females are sexually unresponsive." (True, False, I don’t know) “The sex urge typically increase with age in males over 65." (True, False, I don't know)

“Prescription drugs may alter a person's sex drive." (True, False, I don't know)

"Females after menopause have a physiologically induced need for sexual activity.” (True, False, I don’t know)

"Basically, changes with advanced age (65+) in sexuality involve a slowing of response time rather than a reduction of interest in sex." (True, False, I don't know) 
“Older males typically experience a reduced need to ejaculate and hence may maintain an erection of the penis for a longer time than younger males." (True, False, I don't know)

"Older males and females cannot act as sex partners as both need younger partners for stimulation.” (True, False, I don’t know)

"The most common determinant of the frequency of sexual activity in older couples is the interest of the husband in a sexual relationship with his wife." (True, False, I don't know)

"Barbiturates, tranquilizers, and alcohol may lower the sexual arousal levels of aged persons and interfere with sexual responsiveness." (True, False, I don't know)

"Sexual disinterest in aged persons may be a reflection of a psychological state of depression.” (True, False, I don’t know)

"There is a decrease in frequency of sexual activity with older age in males." (True, False, I don't know)

"There is a greater decrease in male sexuality with age than there is in female sexuality." (True, False, I don't know)

“Heavy consumption of cigarettes may diminish sexual desire.” (True, False, I don't know)

"An important factor in the maintenance of sexual responsiveness in the aging male is the consistency of sexual activity throughout his life." (True, False, I don't know) "Fear of the inability to perform sexually may bring about an inability to perform sexually in older males." (True, False, I don't know) 
"The ending of sexual activity in old age is most likely and primarily due to social and psychological causes rather than biological and physical causes." (True, False, I don't know)

"Excessive masturbation may bring about an early onset of mental confusion and dementia in the aged." (True, False, I don't know)

"There is an inevitable loss of sexual satisfaction in postmenopausal women." (True, False, I don't know)

"Secondary impotence (non-physiologically caused) increased in males over the age of 60 relative to younger males." (True, False, I don't know)

"Impotence in aged males may literally be effectively treated and cured in many instances.” (True, False, I don’t know)

"In the absence of severe physical disability, males and females may maintain sexual interest and activity well into their 80s and 90s.” (True, False, I don't know)

"Masturbation in older males and females has beneficial effects on the maintenance of sexual responsiveness.” (True, False, I don't know)

\section{Risky Behavior Knowledge}

“Contraceptive pills protect against STIs.” (True, False, I don’t know)

"Name as many contraceptive methods as you know."

"Condoms are the only contraceptives that protect against STIs." (True, False, I don't know)

"Name as many STIs as you know."

\section{Subjective Health Literacy Items}


"How often do you have problems learning about a medical condition because of difficulty understanding oral explanations?" (Never, Rarely, Sometimes, More often than not, Always)

"How often do you have problems learning about a medical condition because of difficulty understanding written information?" (Never, Rarely, Sometimes, More often than not, Always)

"How confident are you filling out medical forms by yourself?" (Not at all confident, A little confident, Somewhat confident, Quite a bit confident, Very confident)

“How often do you have someone help you read hospital or medical materials?" (Never, Rarely, Sometimes, More often than not, Always)

"How often do you have someone help you read non-medical materials (newspapers, magazines, mail, etc.)?” (Never, Rarely, Sometimes, More often than not, Always)

\section{Everyday Cognition Battery-Knowledge Subscale}

"Which of the following is highest in sodium?" (Bacon, Mayonnaise, Canned Tomato Juice, Bagel)

"Which of the following is highest in fiber?" (Green Peas, Cheese, Hot Dog, White Bread)

"The problem with cutting coated pills in half is that:" (The medicine is in the coating, They may upset your stomach, You get more medication, This raises the price)

"Dosage is:" (The amount of the drug you take each time, The time of the day you take the drug, The form the medication comes in, The cost of the prescription)

"Current research indicates that eating foods lower in fat decreases your risk for:" (High blood pressure, Nerve disease, Kidney disease, Heart disease) 
"Which of the following is highest in total fat?" (Saltine cracker, Corn, Roast beef, Honey)

"What classification is not a major group in the food pyramid?" (Grain, Meat, Dairy, Desserts)

"Beans are a member of which food group in the food pyramid?" (Dairy, Grain, Vegetable, Meat)

“Don't take aspirin on an empty stomach because:" (It will cause an upset stomach, It will make your head hurt, The aspirin won't enter your blood stream, It can be poisonous)

"When taking a bulk laxative like Metamucil:" (Drink lots of water, Don't drink water to dilute the drug, Don't add artificial flavors, Don't eat a big meal before or after)

"An expiration or "use by" date on a product means:" (The last date the food should be used, The last day the product can be expected to be at its peak quality, The date the food was processed and packaged, None of the above)

"In order to retain as many vitamins as possible when preparing vegetables, you should:" (Cook them thoroughly, Cook them as little as possible, Boil them, Steam them until they are $\operatorname{limp})$

"When a drug expires:" (You should use it up quickly, You should stop taking it, You should see your doctor, You should cut your pills in half to make the prescription last longer) "The "refills" listed on your prescription label means:" (The number of refills of that drug you are allowed, The number of pills to take, The code for renewing the prescription, The time of day you take your medication)

"If you have a high cholesterol level, you have a greater chance of having a:" (Heart attack or stroke, Cancer, Diabetes, None of the above) 
"The relationship between cholesterol and fat is:" (Foods high in cholesterol are high in fat, Foods high in cholesterol are low in fat, The relationship varies with food, There is no relationship)

"Which of the following is probably not a good room in which to store most medications?" (Bedroom, Living Room, Bathroom, Dining Room)

"You should discontinue antibiotics when:" (All finished, Fever or other infectious symptoms go away, Diarrhea continues, You feel better)

"Digoxin is the most common heart medication. Before taking, you should:" (Drink 8 oz. of water, Take pulse, Take blood pressure, Take a potassium supplement)

"After taking a drug, you feel dizzy. You should:" (Stop taking the medication, Call doctor in a few days, Drink more water with the pill, Reduce dosage by half)

\section{Newest Vital Signs}

"Please use the following food label to answer the proceeding questions."

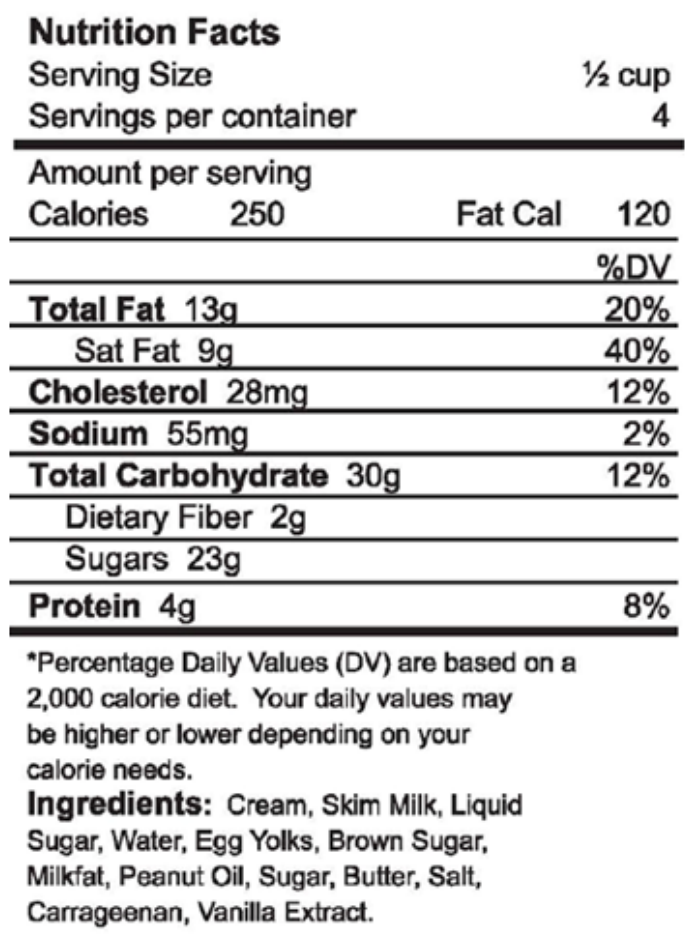


"If I eat the entire container, how many calories will you eat?"

"If you are allowed to have 60 grams of carbohydrates as a snack, how much ice cream could you have?"

"Your doctor advises you to reduce the amount of saturated fat in your diet. You usually have 42 grams of saturated fat each day, which includes one serving of ice cream. If you stop eating ice cream, how many grams of saturated fat would you be consuming each day?"

"If you usually eat 2500 calories in a day, what percentage of your daily value of calories will you be eating if you eat one serving?"

"Pretend that you are allergic to the following substances: penicillin, peanuts, latex gloves, and bee stings. Is it safe for you to eat this ice cream?” (No, Yes, I don't know)

$$
\text { "If no, why not?" }
$$

\section{Numeracy}

"In the Big Bucks Lottery, the chances of winning a $\$ 10.00$ prize is $1 \%$. What is your best guess about how many people would win a $\$ 10.00$ prize if 1000 people each buy a single ticket to Big Bucks?”

"If person A's chance of getting a disease is 1 in 100 in 10 years, and person B's risk is double that of A's, what is B's risk?"

"Which of the following numbers represents the biggest risk of getting a disease?" (1 in $100,1$ in 1000,1 in 10$)$

\section{Health Promotion Lifestyle Profile II}


"Indicate the frequency with which you engage in each of the following behaviors:

Never, Sometimes, Often, Routinely.

"Discuss my problems and concerns with people close to me." (Never, Sometimes, Often, Routinely)

"Chose a diet low in fat, saturated fat, and cholesterol." (Never, Sometimes, Often, Routinely)

"Report any unusual signs or symptoms to a physician or other health professional.” (Never, Sometimes, Often, Routinely)

"Follow a planned exercise program." (Never, Sometimes, Often, Routinely)

“Get enough sleep.” (Never, Sometimes, Often, Routinely)

"Feel I am growing and changing in positive ways." (Never, Sometimes, Often, Routinely)

"Praise other people easily for their achievements." (Never, Sometimes, Often, Routinely)

"Limit use of sugars and food containing sugar (sweets)." (Never, Sometimes, Often, Routinely)

"Read or watch TV programs about improving health.” (Never, Sometimes, Often, Routinely)

"Exercise vigorously for 20 or more minutes at least three times a week (such as brisk walking, bicycling, aerobic dancing, using a stair climber).” (Never, Sometimes, Often, Routinely)

"Take some time for relaxation each day." (Never, Sometimes, Often, Routinely) "Believe that my life has purpose." (Never, Sometimes, Often, Routinely) 
"Maintain meaningful and fulfilling relationships with others." (Never, Sometimes, Often, Routinely)

"Eat 6-11 servings of bread, cereal, rice, and pasta each day." (Never, Sometimes, Often, Routinely)

"Question health professionals in order to understand their instructions." (Never, Sometimes, Often, Routinely)

"Take part in moderate to light activity (such as sustained walking 30-40 minutes 5 or more times a week).” (Never, Sometimes, Often, Routinely)

“Accept those things in my life I cannot change." (Never, Sometimes, Often, Routinely)

"Look forward to the future." (Never, Sometimes, Often, Routinely) "Spend time with close friends." (Never, Sometimes, Often, Routinely)

"Eat 2-4 servings of fruit each day." (Never, Sometimes, Often, Routinely)

“Get a second opinion when I question my health care provider's advice." (Never, Sometimes, Often, Routinely)

“Take part in leisure-time (recreational) physical activities (such as swimming, dancing, bicycling).” (Never, Sometimes, Often, Routinely)

"Concentrate on pleasant thoughts at bedtime." (Never, Sometimes, Often, Routinely)

"Feel content and at peace with myself." (Never, Sometimes, Often, Routinely) "Find it easy to show concern, love, and warmth to others." (Never, Sometimes, Often, Routinely)

"Eat 3-5 servings of vegetables each day." 
"Discuss my health concerns with health professionals." (Never, Sometimes, Often, Routinely)

"Do stretching exercises at least 3 times per week." (Never, Sometimes, Often, Routinely)

"Use specific methods to control my stress." (Never, Sometimes, Often, Routinely)

"Work toward long-term goals in my life." (Never, Sometimes, Often, Routinely)

"Touch and am touched by people I care about." (Never, Sometimes, Often, Routinely)

"Eat 2-3 servings of milk, yogurt or cheese each day." (Never, Sometimes, Often, Routinely)

"Inspect my body at least monthly for physical changes and/or danger signs." (Never, Sometimes, Often, Routinely)

"Get exercise during usual daily activities (such as walking during lunch, using stairs instead of the elevators, parking car away from destination and walking)." (Never, Sometimes, Often, Routinely)

"Balance time between work and play." (Never, Sometimes, Often, Routinely)

"Find each day interesting and challenging." (Never, Sometimes, Often, Routinely)

"Find ways to meet my needs for intimacy." (Never, Sometimes, Often, Routinely)

"Eat only 2-3 servings from the meat, poultry, fish, dried beans, eggs, and nuts group each day.” (Never, Sometimes, Often, Routinely) 
"Ask for information from health professionals about how to take good care of myself." (Never, Sometimes, Often, Routinely)

“Check my pulse rate when exercising." (Never, Sometimes, Often, Routinely)

"Practice relaxation or meditation for 15-20 minutes daily." (Never, Sometimes, Often, Routinely)

"I am aware of what is important to me in life." (Never, Sometimes, Often, Routinely)

“Get support from a network of caring people." (Never, Sometimes, Often, Routinely)

"Read labels to identify nutrients, fat, and sodium content in packaged food." (Never, Sometimes, Often, Routinely)

“Attend educational programs on personal health care.” (Never, Sometimes, Often, Routinely)

"Reach my target heart rate when exercising." (Never, Sometimes, Often, Routinely)

"Pace myself to prevent tiredness." (Never, Sometimes, Often, Routinely) "Feel connected with some force greater than myself." (Never, Sometimes, Often, Routinely)

"Settle conflicts with others through discussion and compromise." (Never, Sometimes, Often, Routinely)

"Eat breakfast." (Never, Sometimes, Often, Routinely) "Seek guidance or counseling when necessary." (Never, Sometimes, Often, Routinely) 
"Expose myself to new experiences and challenges." (Never, Sometimes, Often, Routinely)

"Drink at least 8 glasses of water daily." (Never, Sometimes, Often, Routinely)

\section{Health Screens}

"Have you had a screen or check for..."

"Obesity: BMI?"

"Cholesterol Screening?"

"High blood pressure?"

"Diabetes screen?"

"HIV screen?"

"Other sexually transmitted disease screens?"

"Skin cancer screen?"

"Dental screen?"

"Hearing screen?"

"Vision screen/eye exam?"

"Glaucoma screen?"

"Breast cancer screen?"

"Cervical cancer screen?"

"Colorectal cancer screen (colonoscopy)?"

“Osteoporosis screen (bone density tests)?"

"Other screens not previously listed?"

\section{Everyday Cognition Battery-Reasoning}


"In the chart below you will see two drugs listed "Drug 1" and "Drug 2." The third column tells you what will happen if you take these two medications at the same time. Use the chart below to answer the questions that follow."

\begin{tabular}{|l|l|l|}
\hline \multicolumn{1}{|c|}{ Drug 1 } & \multicolumn{1}{c|}{ Drug 2 } & Possible side effects \\
\hline $\begin{array}{l}\text { Lanoxin } \\
\text { (cardiac pill) }\end{array}$ & $\begin{array}{l}\text { Lasix } \\
\text { (water pill) }\end{array}$ & $\begin{array}{l}\text { rash, vomiting, } \\
\text { headache, irregular } \\
\text { heartbeat, fever }\end{array}$ \\
\hline $\begin{array}{l}\text { Capoten } \\
\text { (blood pressure } \\
\text { pill) }\end{array}$ & $\begin{array}{l}\text { Lasix } \\
\text { (water pill) }\end{array}$ & $\begin{array}{l}\text { rash, nausea, } \\
\text { irregular heartbeat }\end{array}$ \\
\hline $\begin{array}{l}\text { Capoten } \\
\text { (blood pressure } \\
\text { pill) }\end{array}$ & $\begin{array}{l}\text { Genuine Bayer } \\
\text { Aspirin } \\
\text { (pain reliever) }\end{array}$ & $\begin{array}{l}\text { chest pain, } \\
\text { vomiting, nausea, }\end{array}$ \\
\hline $\begin{array}{l}\text { Genuine Bayer } \\
\text { Aspirin } \\
\text { (pain reliever) }\end{array}$ & $\begin{array}{l}\text { Maalox } \\
\text { (antacid) }\end{array}$ & $\begin{array}{l}\text { fever, confusion, } \\
\text { headache }\end{array}$ \\
\hline
\end{tabular}

"What kind of pill is Lasix?"

"Name two of the side effects listed for Aspirin and Maalox."

"Name one of the medication names under the heading of Drug 1."

"Mr. Albert takes two medications at 5PM. One of the medications was taken

because of a severe headache. Twenty minutes later he begins to feel extremely nauseous. Which likely combination of drugs did Mr. Albert take?"

"One drug taken in combination with several other medications often causes irregular heartbeat. Which drug might this be?"

"When Mr. Albert takes Bayer and Maalox, what possible side effect could he get that is different from any of the other symptoms listed in the chart?"

"If Mr. Albert is taking Capoten for high blood pressure should he take Aspirin at the same time?" 
"Below is a recent chart detailing the benefits offered by Medicare. Use the information below to answer the questions that follow."

MIEDICARE (PART A): HOSPITAL INSURANCE COVERED SERVICES FOR 1996

\begin{tabular}{|c|c|c|c|}
\hline Services & Benefit & Medicare Pays & You Pay \\
\hline $\begin{array}{l}\text { HOSPITALIZATION } \\
\text { Semiprivate room and board, } \\
\text { general nursing and other hospital } \\
\text { services and supplies }\end{array}$ & $\begin{array}{l}\text { First } 60 \text { days } \\
61 \text { st to } 90 \text { th day } \\
91 \text { st to } 150 \text { th day } \\
\text { beyond } 150 \text { days }\end{array}$ & $\begin{array}{l}\text { All but } \$ 736 \\
\text { All but } \$ 184 \text { a day } \\
\text { All but } \$ 368 \text { a day } \\
\text { Nothing }\end{array}$ & $\begin{array}{l}\$ 736 \\
\$ 184 \text { a day } \\
\$ 368 \text { a day } \\
\text { All costs }\end{array}$ \\
\hline $\begin{array}{l}\text { SKILLED NURSING } \\
\text { FACILITY CARE } \\
\text { Semiprivate room and board, } \\
\text { general mursing and other hospital } \\
\text { services and supplies. }{ }^{* *}\end{array}$ & $\begin{array}{l}\text { First } 20 \text { days } \\
\text { Additional } 80 \text { days } \\
\text { Beyond } 100 \text { days }\end{array}$ & $\begin{array}{l}100 \% \text { of approved amount } \\
\text { All but } \$ 92 \text { a day } \\
\text { Nothing }\end{array}$ & $\begin{array}{l}\text { Nothing } \\
\text { Up to } \$ 92 \text { a day } \\
\text { All costs }\end{array}$ \\
\hline $\begin{array}{l}\text { HOME HEALTH CARE } \\
\text { Part-time or intermittent skilled } \\
\text { care, home health aide services, } \\
\text { durable medical equipment and } \\
\text { supplies and other services }\end{array}$ & $\begin{array}{l}\text { Unlimited as long as } \\
\text { you meet Medicare } \\
\text { requirements for } \\
\text { home health care } \\
\text { benefits. }\end{array}$ & $\begin{array}{l}80 \% \text { of approved amount for } \\
\text { durable medical equipment }\end{array}$ & $\begin{array}{l}\text { Nothing for } \\
\text { services; } 20 \% \text { of } \\
\text { approved amount } \\
\text { for durable } \\
\text { medical } \\
\text { equipment. }\end{array}$ \\
\hline $\begin{array}{l}\text { HOSPICE CARE } \\
\text { Pain relief, symptom management } \\
\text { and support services for the } \\
\text { terminally ill. }\end{array}$ & $\begin{array}{l}\text { For as long as doctor } \\
\text { certifies need. }\end{array}$ & $\begin{array}{l}\text { All but limited costs for out } \\
\text { patient drugs and inpatient respite } \\
\text { care. }\end{array}$ & $\begin{array}{l}\text { Limited cost } \\
\text { sharing for } \\
\text { outpatient drugs } \\
\text { and inpatient } \\
\text { respite care. }\end{array}$ \\
\hline $\begin{array}{l}\text { BLOOD } \\
\text { When furnished by a hospital or } \\
\text { skilled nursing facility during a } \\
\text { covered stay. }\end{array}$ & $\begin{array}{l}\text { Unlimited during a } \\
\text { benefit period if } \\
\text { medically necessary. }\end{array}$ & $\begin{array}{l}\text { All but first } 3 \text { pints per calendar } \\
\text { year. }\end{array}$ & $\begin{array}{l}\text { For first } 3 \\
\text { pints.*** }\end{array}$ \\
\hline
\end{tabular}

* 60 reserve days may be used only once

** Neither Medicare nor Medigap insurance will pay for most nursing home care

*.. To the extent the three pints of blood are paid for or replaced under one part of Medicare during the calendar year, they do not have to be paid for or replaced under the other part.

"What is the name of the insurance described in the chart above?"

"Does this insurance cover hospitalization?"

"Does this insurance cover home health care aides?"

"If you had a very serious illness so that you had to stay in the hospital for a long time, how much would you have to pay starting on the $91^{\text {st }}$ day?"

"If you are approved, how much do you have to pay for medical equipment such as a wheelchair or walker?"

"If you receive hospice care, what do you have to help pay for?" 
"As you move into the sixth month in the hospital how much of the costs do you have to pay?"

"Mr. Cole is taking the three medications listed below. On Sunday night, he decides he is going to put all his pills for the week into a pill box that is divided into chambers for morning, noon, evening, and bedtime, for every day of the week. Use the labels below to answer the questions that follow."

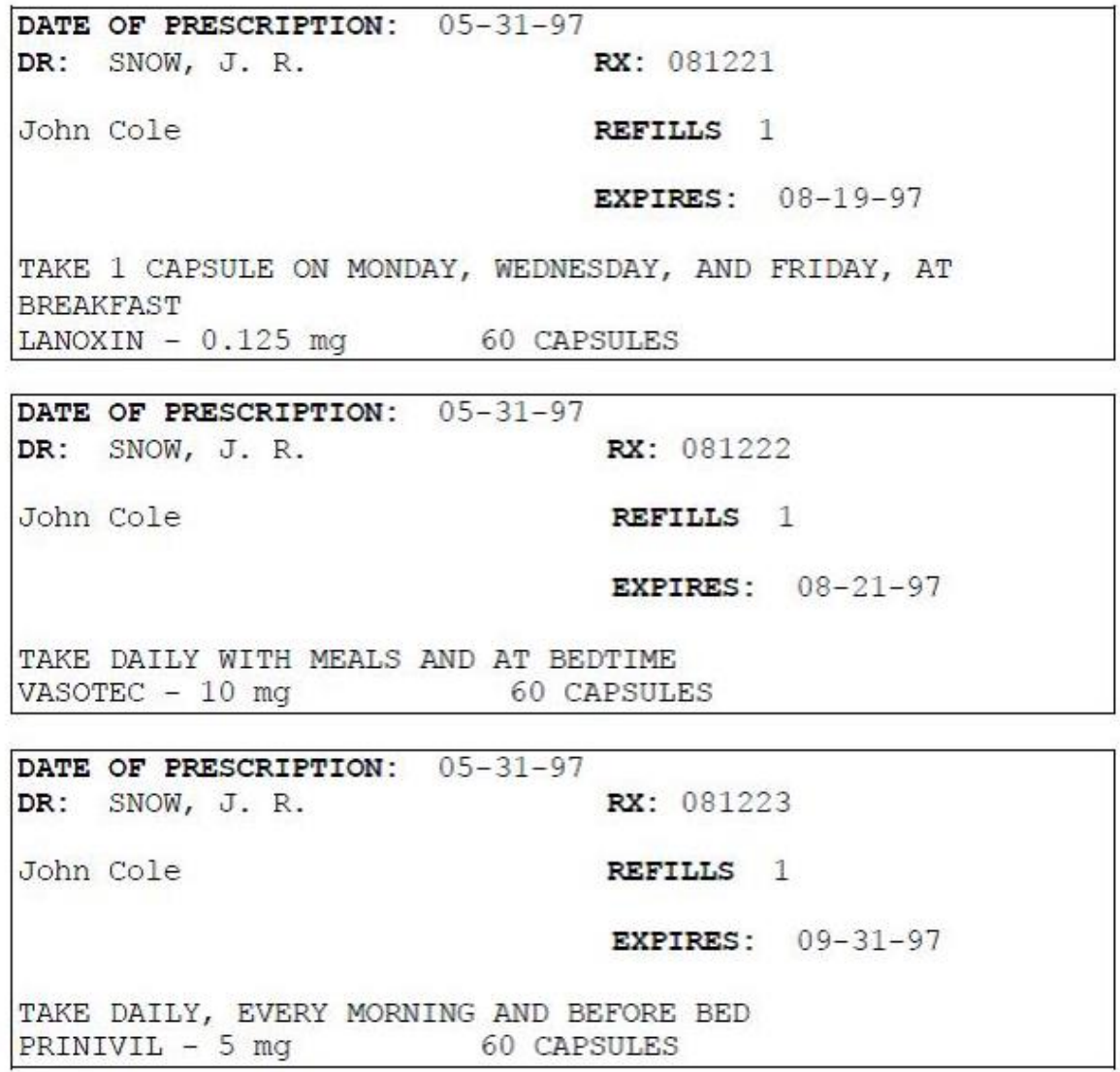

"Name the doctor who prescribed these three medications."

"What is the patient's first name?"

"How many different medications is the patient taking?"

"How many pills should be in the Wednesday chamber?" 
"How many pills will Mr. Cole take every night before he goes to bed?"

"What is the total number of pills Mr. Cole should take on Saturday?"

"By 2:00 PM on Tuesday, how many pills should Mr. Cole have taken for the day?"

"Miss Braun wants a can of chili as part of her dinner. She goes to her cabinet and finds two different cans of chili. The labels for both cans are displayed below. Based on the information found on these labels answer the questions that follow."

CHILI

BRAND A

\begin{tabular}{|c|c|}
\hline \multicolumn{2}{|c|}{$\begin{array}{l}\text { Nutrition Facts } \\
\text { Serving Size } 1 \text { cup }(236 \mathrm{~g}) \\
\text { Servings Per Container about } 2\end{array}$} \\
\hline \multicolumn{2}{|c|}{ Amount Per Serving } \\
\hline \multicolumn{2}{|c|}{ Calories $410 \quad$ Calories from Fat 270} \\
\hline & \%oally values' \\
\hline TotalFat $30 \mathrm{~g}$ & $46 \%$ \\
\hline Saturated Fat 13 & $61 \%$ \\
\hline Cholest. $75 \mathrm{mg}$ & $25 \%$ \\
\hline Sodium $950 \mathrm{mg}$ & $39 \%$ \\
\hline Total Carbohydrate $16 \mathrm{~g}$ & $5 \%$ \\
\hline Dietary Fiber $4 \mathrm{~g}$ & $14 \%$ \\
\hline \multirow{2}{*}{\multicolumn{2}{|c|}{$\frac{\text { Sugars } 4 \mathrm{~g}}{\text { Protein } 20 \mathrm{~g}}$}} \\
\hline & \\
\hline Viatmin A 26\% & Vitamin $\mathrm{CO} \%$ \\
\hline $\begin{array}{ll}\text { Calcium } 4 \% & ? \\
\text { Percent Daly Vasues are bosed }\end{array}$ & $\begin{array}{c}\text { Iron } 18 \% \\
\text { on } 2,000 \text { calorie det }\end{array}$ \\
\hline
\end{tabular}

\section{CHILI}

BRAND B

\begin{tabular}{|c|c|}
\hline \multicolumn{2}{|c|}{$\begin{array}{l}\text { Nutrition Facts } \\
\text { Serving Size } 1 \text { cup }(236 \mathrm{~g}) \\
\text { Servings Per Container about } 2\end{array}$} \\
\hline \multicolumn{2}{|l|}{ Amount Per Serving } \\
\hline \multicolumn{2}{|c|}{ Calories $190 \quad$ Calories from Fat 25 } \\
\hline & \%oally values: \\
\hline Total Fat $3 g$ & $5 \%$ \\
\hline Saturated Fat $1 \mathrm{~g}$ & $5 \%$ \\
\hline Cholest. $75 \mathrm{mg}$ & $25 \%$ \\
\hline Sodium $1250 \mathrm{mg}$ & $52 \%$ \\
\hline Total Carbohydrate $17 \mathrm{~g}$ & $6 \%$ \\
\hline Dietary Fiber $3 g$ & $12 \%$ \\
\hline \multirow{2}{*}{\multicolumn{2}{|c|}{$\begin{array}{c}\text { Sugars } 3 \mathrm{~g} \\
\text { Protein } 19 \mathrm{~g}\end{array}$}} \\
\hline & \\
\hline Vitamin A 25\% $n$ & Vitamin C $0 \%$ \\
\hline $\begin{array}{lc}\text { Calcium } 3 \% \\
\text { Percent Daly Vivues are byredo }\end{array}$ & $\begin{array}{l}\text { Iron } 15 \% \\
2.000 \text { calonit बet }\end{array}$ \\
\hline
\end{tabular}


"What product are these nutrition labels for?"

"What is the serving size in brand A?"

"How many mg. of sodium are in brand B?"

"Miss Braun needs to avoid foods that are high in fat; which can of chili would she be more likely to eat?"

"If she selects Brand B, which categories will she get more of?"

"Which category does both cans of chili have the exact amount of?"

"If she wanted to cut down on her intake of salt, which can of chili would she want to avoid?"

"Below you see what Mrs. Carver ate for the entire day in the first column. In the second column, is a list of the number of servings Mrs. Carver had for each food group. Use this list and the food pyramid below to answer the questions that follow."

\section{BREAKFAST}

2 pancakes

$4 \mathrm{oz}$. orange juice

$1 / 2$ grapefruit

\section{$\underline{\text { LUNCH }}$}

2 slices of cheese pizza

$8 \mathrm{oz}$ of coke

DINNER

1 whole wheat roll

$6 \mathrm{oz}$. broiled steak

1 cup of mixed greens

2 cups of salad

SNACKS

1 candy bar

1 apple

1 cup of popcorn

\section{SERVINGS}

1 bread and 1 fat

1 fruit

1 fruit

2 breads, 2 milks, $1 / 2$ veg.

sweets

1 bread

2 protein

$1 \mathrm{veg}$.

2 veg.

fats and sweets

1 fruit

1 bread 


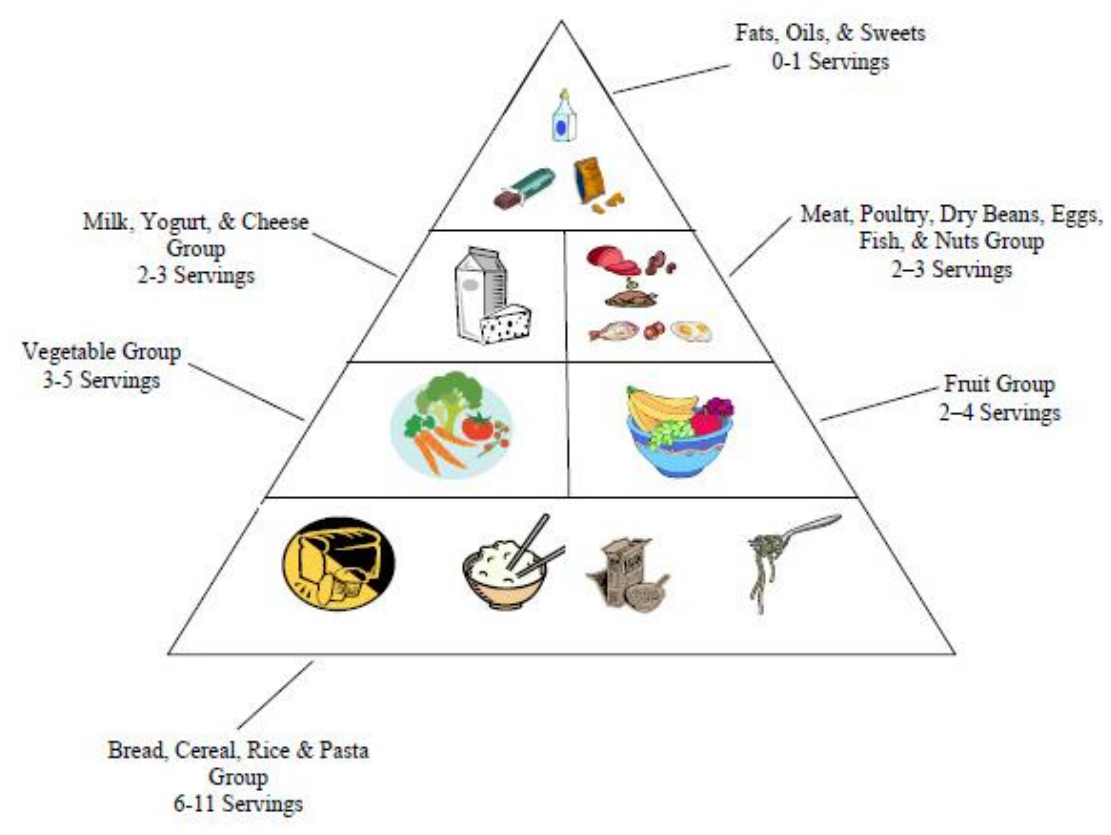

"Name three of the foods on this food list from the bread and cereals food group."

"Name one of the foods that were eaten as a snack."

"Across the food groups, how many total servings did Mrs. Carver eat for dinner?"

"Looking at what Mrs. Carver ate for the entire day, what food group did she not eat enough of?"

"How many bread servings did Mrs. Carver eat for the entire day?"

"According to the food pyramid, how many more fruits and meat servings does she need to eat today?"

"According to the food pyramid, which food group did she eat too much of today?"

\section{Religion Items}

"In terms of religious activities..."

"I attend religious services." (Never, Almost Never, Sometimes, Very Often) 
"I attend religious meetings or missions." (Never, Almost Never, Sometimes, Very Often)

"I listen to religious services on the radio or TV." (Never, Almost Never, Sometimes, Very Often)

"I contribute money to my church or synagogue." (Never, Almost Never, Sometimes, Very Often)

"I take part in various religious organizations." (Never, Almost Never, Sometimes, Very Often)

"I read the Bible, Torah, or other holy books." (Never, Almost Never, Sometimes, Very Often)

"I pray alone." (Never, Almost Never, Sometimes, Very Often)

"I pray with others." (Never, Almost Never, Sometimes, Very Often)

\section{The Gratitude Questionnaire-Six Item Form}

"Please indicate how much you agree or disagree with each statement."

"I have so much in life to be thankful for." (Strongly disagree, Disagree, Slightly disagree, Neutral, Slightly agree, Agree, Strongly agree)

"If I had to list everything I was grateful for, it would be a very long list." (Strongly disagree, Disagree, Slightly disagree, Neutral, Slightly agree, Agree, Strongly agree)

"When I look at the world, I don't see much to be grateful for." (Strongly disagree, Disagree, Slightly disagree, Neutral, Slightly agree, Agree, Strongly agree)

"I am grateful to a wide variety of people." (Strongly disagree, Disagree, Slightly disagree, Neutral, Slightly agree, Agree, Strongly agree) 
"As I get older I find myself more able to appreciate the people, events, and situations that have been a part of my life history." (Strongly disagree, Disagree, Slightly disagree, Neutral, Slightly agree, Agree, Strongly agree)

"Long amounts of time can go by before I feel grateful to something or someone." (Strongly disagree, Disagree, Slightly disagree, Neutral, Slightly agree, Agree, Strongly agree)

\section{Demographics}

"What is your current age?"

"What is your marital status?" (Married/Partnered, Widowed, Divorced, Single, Never Married, Other)

If other, please specify.

“To which racial group do you belong?” (White, African American/Black, American Indian or Alaska Native, Latin American/Hispanic, Native Hawaiian, Pacific Islander, or Asian, Two or More Races, Other)

"What is your current work status?" (Employed-Full Time, Employed-Part Time, Retired, Unemployed/Homemaker, Self Employed, Other)

If other, please specify.

"How much difficulty do you have paying your bills?" (A great deal of difficulty, Some difficulty, A little difficulty, No difficulty)

"What is the highest grade or level of education you have completed?" (11 or fewer years, High school/GED, Some college or technical training after high school, Associate's degree (2-yr), Bachelor's degree (4 yr.), More than a Bachelor's degree)

"Have you served in the military?" 
"Indicate highest rank (if yes)"

"Politically, do you consider yourself:" (Extremely Liberal, Liberal, Slightly Liberal, Moderate/Middle of the road, Slightly Conservative, Conservative, Extremely Conservative)

"What is your sex?" (Male, Female)

"How many children do you have?"

“How often do you interact with older adults (over the age of 65 years)?" (Never, Occasionally, Monthly, Weekly, Daily)

"Do you currently act as a caregiver to anyone over the age of 65?"

“How often do you interact with children (under the age of 15 years)?” (Never,

Occasionally, Monthly, Weekly, Daily)

"Are you a participant recruited through Mechanical Turk?"

"Please enter you Mechanical Turk ID below."

\section{Medical Conditions}

"Please indicate which conditions you have and the amount of difficulty each causes you."

“Arthritis" (No difficulty, Mild difficulty, Moderate Difficulty, Severe difficulty, I do not have this condition)

"Heart Trouble" (No difficulty, Mild difficulty, Moderate Difficulty, Severe difficulty, I do not have this condition

“Diabetes" (No difficulty, Mild difficulty, Moderate Difficulty, Severe difficulty, I do not have this condition)

“High Blood Pressure” (No difficulty, Mild difficulty, Moderate Difficulty, Severe difficulty, I do not have this condition) 
“Sexual Dysfunction” (No difficulty, Mild difficulty, Moderate Difficulty, Severe difficulty, I do not have this condition)

"Cancer" (No difficulty, Mild difficulty, Moderate Difficulty, Severe difficulty, I do not have this condition)

"Emphysema" (No difficulty, Mild difficulty, Moderate Difficulty, Severe difficulty, I do not have this condition)

"Other (please specify condition(s) and amount of difficulty it causes you)" 


\section{Appendix B}

Table B1. Partial correlations between the sexuality variables with the effects of race statistically controlled.

\begin{tabular}{|c|c|c|c|c|c|c|}
\hline Measure & 2 & 3 & 4 & 5 & 6 & 7 \\
\hline 1. Freq. of Sexual Activity & $.86^{* *}$ & $.88 * *$ & $.53 * *$ & -.05 & $-.24 * *$ & $.19 * *$ \\
\hline 2. Satisfaction-Overall & -- & $.93 * *$ & $.51 * *$ & -.04 & $-.26 * *$ & $.20 * *$ \\
\hline 3. Satisfaction-Composite & & -- & $.51 * *$ & -.01 & $-.27 * *$ & $.20 * *$ \\
\hline 4. Interest Scale & & & -- & $-.30 * *$ & $-.34 * *$ & $.17 *$ \\
\hline 5. NSHAP Sexual Mores & & & & -- & $.29 * *$ & -.04 \\
\hline 6. ASKAS Attitudes Subscale & & & & & -- & $-.24 * *$ \\
\hline 7. ASKAS Knowledge Subscale & & & & & & -- \\
\hline
\end{tabular}

Note . NSHAP = National Social Life, Health, and Aging Project; ASKAS = Aging Sexual

Knowledge and Attitudes Scale.

${ }^{*} p<.01 .{ }^{* *} p<.001$. 


\section{Appendix C}

The components of the successful aging model were also entered as a measurement model into AMOS to see if similar results would be obtained. The same variables that were used in the exploratory factor analysis were used. The overall fit model fit statistics indicate an acceptable, but not optimal fit, $\chi^{2}(24, N=361)=70.52, p<.001$; AGFI $=.925$; TLI $=.967$; and RMSEA $=.073$. Modification indices indicate that some observed measures may statistically relate to multiple constructs, such as General Health with both Physical and Psychological WellBeing. For the purposes of this exploratory investigation, no modifications were made. All of the hypothesized paths were significant with strong beta weights; these are listed in Table C1 below. Additionally, there was no evidence of multicollinearity across the three latent constructs. Sexual Well-Being related moderately to both Physical $(r=.32)$ and Psychological Well-Being $(r=$ .39). Physical and Psychological Well-Being also related highly with one another $(r=.47)$. 
Table C1. Confirmatory factor analysis results for successful aging model with sexual well-being component.

\begin{tabular}{lccc}
\hline \multicolumn{1}{c}{ Variable } & $b(S E)$ & $\beta$ & CR \\
\hline Sexual Well-Being $(s W B)$ & & & \\
Frequency in Past Year $\rightarrow$ sWB & 1.00 & .91 & 32.24 \\
Overall Satisfaction $\rightarrow$ sWB & $2.23(.07)$ & .95 & 34.43 \\
Component Satisfaction $\rightarrow$ sWB & $6.61(.19)$ & .97 & \\
Physical Well-Being $($ phyWB $)$ & & & \\
Physical Functioning $\rightarrow$ phyWB & 1.00 & .79 & 11.06 \\
Physical Roles $\rightarrow$ phyWB & $1.42(.13)$ & .74 & 10.24 \\
General Health $\rightarrow$ phyWB & $.69(.07)$ & .64 & \\
Psychological Well-Being $($ psyWB $)$ & & & \\
Subjective Happiness $\rightarrow$ psyWB & 1.00 & .83 & 15.13 \\
Positive Affect $\rightarrow$ psyWB & $2.54(.17)$ & .79 & 15.07 \\
Mental Health $\rightarrow$ psyWB & $15.54(1.03)$ & .79 & \\
\hline
\end{tabular}

Note. $\mathrm{CR}=$ Critical Ratio. For critical ratios $>1.96, p<.05$. 


\section{Appendix D}

An independent samples t-test was used to investigate differences on the sexuality measures of interest based on sexual orientation. The sexual orientation variable was dichotomized to represent those who identified as mainly heterosexual in comparison to those who identified as bisexual or homosexual. Heterosexuals were found to differ significantly from those identifying otherwise on general sexual attitudes, $t(398)=2.83, p=.005$, Cohen's $d=.58$. Those identifying as bisexual or homosexual expressed more permissive sexual values $(M=$ $12.55, S D=2.95)$ than those identifying as heterosexual $(M=14.43, S D=3.48)$. The two groups also differed marginally on self-reported sexual interest, $t(398)=-2.07, p=.037$, Cohen's $d=$ .39. Heterosexuals reported lower levels of sexual interest $(M=3.82, S D=1.22)$ than the bisexual/homosexual group $(M=4.31, S D=1.29)$. Given that both of these variables are of particular interest to the hypotheses being advanced, a decision was made to remove those identifying as bisexual or homosexual from further analyses. They did not differ significantly from the remaining sample on age, gender, or race. 